\title{
Article \\ Internalization of Polymeric Bacterial Peptidoglycan Occurs through Either Actin or Dynamin Dependent Pathways
}

\author{
Narcis I. Popescu ${ }^{1, *(1)}$, Jackie Cochran ${ }^{1}$, Elizabeth Duggan ${ }^{1}$, Jędrzej Kluza ${ }^{1}$, Robert Silasi ${ }^{2}$ \\ and Kenneth Mark Coggeshall ${ }^{1, *}$ \\ 1 Department of Arthritis and Clinical Immunology, Oklahoma Medical Research Foundation, \\ Oklahoma City, OK 73104, USA; jackie-cochran@omrf.org (J.C.); elizabeth-duggan@omrf.org (E.D.); \\ jedrzej-kluza@omrf.org (J.K.) \\ 2 Cardiovascular Biology Research Program, Oklahoma Medical Research Foundation, \\ Oklahoma City, OK 73104, USA; robert-silasimansat@omrf.org \\ * Correspondence: narcis-popescu@omrf.org (N.I.P.); mark-coggeshall@omrf.org (K.M.C.)
}

\section{check for} updates

Citation: Popescu, N.I.; Cochran, J.; Duggan, E.; Kluza, J.; Silasi, R.; Coggeshall, K.M. Internalization of Polymeric Bacterial Peptidoglycan Occurs through Either Actin or Dynamin Dependent Pathways. Microorganisms 2022, 10, 552. https://doi.org/10.3390/ microorganisms10030552

Academic Editor: Michael K.

Mansour

Received: 27 January 2022

Accepted: 28 February 2022

Published: 3 March 2022

Publisher's Note: MDPI stays neutral with regard to jurisdictional claims in published maps and institutional affiliations.

Copyright: (c) 2022 by the authors. Licensee MDPI, Basel, Switzerland. This article is an open access article distributed under the terms and conditions of the Creative Commons Attribution (CC BY) license (https:// creativecommons.org/licenses/by/ $4.0 /)$.

\begin{abstract}
Peptidoglycan (PGN), a polymeric glycan macromolecule, is a major constituent of the bacterial cell wall and a conserved pathogen-associated molecular pattern (PAMP) that triggers immune responses through cytosolic sensors. Immune cells encounter both PGN polymers and hydrolyzed muropeptides during infections, and primary human innate immune cells respond better to polymeric PGN than the minimal bioactive subunit muramyl dipeptide (MDP). While MDP is internalized through macropinocytosis and/or clathrin-mediated endocytosis, the internalization of particulate polymeric PGN is unresolved. We show here that PGN macromolecules isolated from Bacillus anthracis display a broad range of sizes, making them amenable for multiple internalization pathways. Pharmacologic inhibition indicates that PGN primarily, but not exclusively, is internalized by actin-dependent endocytosis. An alternate clathrin-independent but dynamin dependent pathway supports $20-30 \%$ of PGN uptake. In primary monocytes, this alternate pathway does not require activities of RhoA, Cdc42 or Arf6 small GTPases. Selective inhibition of PGN uptake shows that phagolysosomal trafficking, processing and downstream immune responses are drastically affected by actin depolymerization, while dynamin inhibition has a smaller effect. Overall, we show that polymeric PGN internalization occurs through two endocytic pathways with distinct potentials to trigger immune responses.
\end{abstract}

Keywords: peptidoglycan; bacteria; monocytes; internalization; CIE

\section{Introduction}

Recognition and cellular processing of invading pathogens and/or pathogen-associated molecular patterns (PAMPs) are critical for mounting appropriate immune responses during infections. Many pathogens have developed mechanisms to hijack endocytic machineries to either avoid recognition and internalization by immune cells, or to redirect their intracellular trafficking away from the lysosomal compartment [1]. In response, immune cells maintain and use a diverse repertoire of partially overlapping internalization pathways, including phagocytosis, macropinocytosis, dynamin-dependent and dynamin-independent pathways [2-4], that allows them to sample the environment even when one or more of the molecular components are targeted by virulence factors. Understanding molecular disturbances of endocytic pathways during infections could elucidate immune impairment and provide new targets for infection prophylaxis [5].

Peptidoglycan (PGN) is a ubiquitous component of the bacterial cell wall, abundantly expressed by Gram-positive (Gram+) bacteria. It is a polymeric macromolecule comprised of linear glycan repeats of $\mathrm{N}$-acetylglucosamine- $\beta(1,4)-\mathrm{N}$-acetylmuramic acid disaccharides, crosslinked by intercalating small peptides. PGN diversity resides in variations in the stem peptides and post synthetic modifications of glycan strands [6] which, in 
turn, can modulate downstream immune recognition and responses [7-9]. PGN and/or its bioactive fragments are recognized by a variety of immune sensors, including serum opsonins [10-12], peptidoglycan recognition proteins (PGLYRPs) [13] and intracellular sensors such as nucleotide-binding oligomerization domain (NOD) proteins NOD1 and NOD2 [9,14] and inflammasomes NLRP1 [15] and NLRP3 [7]. In general, PGN supports proinflammatory immune responses during acute Gram-positive (Gram+) [12,16] and Gram-negative (Gram-) infections [17] and chronic inflammatory pathologies after disruption of intestinal permeability $[18,19]$.

Given the cytosolic distribution of NODs and inflammasomes, PGN, either polymeric macromolecules and/or monomer subunits, have to be internalized by immune cells [20]. The internalization pathway likely depends on how PGN is presented to immune cells. During growth, both Gram+ and Gram - bacteria release PGN subunits into the environment during continuous remodeling of the cell wall. These fragments, likely uncoupled peptidyl-disaccharides biosynthetic modules [21,22] or hydrolyzed muropeptides [23], are internalized by clathrin and dynamin-mediated endocytosis (CME) [24] and transported to cytosol by endolysosomal peptide transporters [25]. Many bacteria, both Gram - and Gram+, also release membrane vesicles (BMVs) containing cell wall components [26]. While their immune recognition and endocytosis is not fully understood, BMVs trigger NOD-dependent immune responses indicative of PGN processing [27,28]. Furthermore, immune-mediated extracellular killing of pathogens $[29,30]$ will lead to fragmentation and release of bacterial cell wall components including polymeric PGN and hydrolyzed muropeptides. We previously observed that human immune cells respond better to polymeric peptidoglycan compared to muramyl-dipeptide (MDP) subunits [31], indicating efficient uptake of these macromolecules. In this study, we explored the internalization mechanisms of polymeric PGN in primary human monocytes and show that, in contrast to MDP, PGN macromolecules are mainly internalized through actin-dependent phagocytosis, with a clathrin-independent but dynamin-dependent alternate pathway responsible for $20-30 \%$ of the uptake. Selective inhibition of these endocytic pathways impairs phagolysosome trafficking and reduces immune responses to PGN.

\section{Materials and Methods}

\subsection{Materials}

Cell culture RPMI-1640 media and supplements were from either ATCC (Manassas, VA, USA) or Corning (Manassas, VA, USA). Cell culture grade Hank's buffer salt solution (HBSS), Dulbecco's phosphate buffer saline (DPBS), dimethyl sulfoxide (DMSO), FITC (fluorescein isothiocyanate) and Histopaque-1077 were from Millipore-Sigma (St. Louis, MO, USA). Bovine serum albumin (BSA), MACS grade, was from Miltenyi Biotec (Auburn, CA, USA). Peptidoglycan (PGN) was isolated

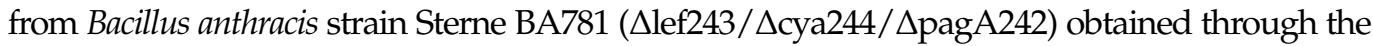
NIH Biodefense and Emerging Infections Research Resources Repository (NR-9401), National Institute of Allergy and Infectious Diseases, National Institutes of Health. The Trypticase Soy Broth was from BD Biosciences (San Jose, CA, USA). Bacteria and PGN were labeled with either FITC or biotin (EZ-link Sulfo-NHS-LC-Biotin, Pierce Biotechnology, Rockford, IL, USA). Sizing fluorescent calibrator nanobeads were from Spherotech (Lake Forest, IL, USA). The endocytic inhibitors latrunculin B (Lat.B), hydroxy-dynasore (OH-Dyn.), Y16, rhosin, ML141 and secin H3 were from EMD Millipore (Billerica, MA, USA), ES9-17 was from Sigma, and NAV 2729 was purchased from Tocris (Minneapolis, MN, USA). For flow cytometry, we used phycoerythrin (PE) or PE-Cyanine7 labeled anti-human CD14 (clone 61D3), FITC labeled anti-human TNF (clone MAb11) and allophycocyanin (APC) labeled anti-human TF/CD142 (clone HTF-1). All cytometry monoclonals and isotype controls were from eBioscience (San Diego, CA, USA). Viability stains, either Zombie Violet or Zombie Aqua, were from BioLegend (San Diego, CA, USA). Trypan Blue (4\%) was from Gibco (Waltham, MA, USA). For immunofluorescence microscopy, we used biotinylated mouse anti-human CD14 monoclonals (clones 61D3, Novus Biologicals, Centennial, CO, USA; Tuk4, Invitrogen, Carlsbad, CA, USA; and MEM-15, GeneTex, Irvine, CA, USA), rabbit 
monoclonal anti-human lysosomal-associated membrane protein 1 (LAMP1/CD107a, clone 107, Novus Biologicals, Centennial, CO, USA), cyanine3-labeled streptavidin and cyanine5labeled donkey anti-rabbit IgG (both from Jackson ImmunoResearch, West Grove, PA, USA). Saponin and the nuclear counterstain DAPI (4',6-diamidino-2-phenylindole) dilactate were from Millipore-Sigma (St. Louis, MO, USA), while the ProLong Gold mounting medium was from Life Technologies (Carlsbad, CA, USA). All other chemicals were ACS or cell culture grade and purchased from either Sigma or Fisher Scientific (Waltham, MA, USA).

\subsection{Analysis of Primary Human Peripheral Blood Mononuclear Cells}

Studies on peripheral blood mononuclear cells (PBMCs) were conducted based on a protocol approved by the Institutional Review Board at the Oklahoma Medical Research Foundation (protocol number 19-11) and in accordance with the Declaration of Helsinki. Voluntary participants self-enrolled, were informed of study aims and procedures, and gave written informed consent. Samples were de-identified and coded by the study phlebotomist before experiments. PBMCs were isolated by density gradient centrifugation using Histopaque-1077, washed twice with HBSS and transferred to RPMI-1640 media supplemented with glucose and glutamine. PBMCs were pre-treated with endocytic inhibitors for $1 \mathrm{~h}$ in the absence of serum in a humidified atmosphere containing $5 \% \mathrm{CO}_{2}$, and the inhibitors were maintained throughout the experiment. For internalization studies, treated cells were incubated with pre-opsonized particles, either PGN or heat-killed Bacillus anthracis $(\mathrm{hkBa})$, in a thermostated benchtop water bath at $37^{\circ} \mathrm{C}$ for $30 \mathrm{~min}$. For activity assays, cells were stimulated with PGN for $6 \mathrm{~h}$ at $37^{\circ} \mathrm{C}$ in a humidified atmosphere containing $5 \% \mathrm{CO}_{2}$.

\subsection{Bacteria Strain, Peptidoglycan Purification and Labeling}

Bacillus anthracis strain Sterne BA781 was grown in trypticase soy broth, heat inactivated for $1 \mathrm{~h}$ at $70^{\circ} \mathrm{C}$ and used at $1 \times 10^{7} \mathrm{cfu}$ equivalents $/ \mathrm{mL}$ [32,33]. Anthrax PGN was purified from the BA781 Sterne strain parental bacteria according to protocols detailed previously [8,20,34]. Purified PGN preparations were free of TLR2 and TLR4 agonists [8] and supported internalization-dependent proinflammatory and procoagulant responses in primary human monocytes [11,32].

PGN and $\mathrm{hkBa}$ particles were amine labeled using either FITC (Millipore-Sigma, St. Louis, MO, USA) or EZ-link Sulfo-NHS-LC-Biotin (Pierce Biotechnology, Waltham, MA, USA) for $1 \mathrm{~h}$ at room temperature in carbonate buffer of $\mathrm{pH}$ 9.0. Particles were collected by centrifugation, quenched with $0.1 \mathrm{M}$ glycine, then washed extensively with HBSS and stored in HBSS.

\subsection{Sizing of PGN Polymers Purified from Bacterial Cell Wall}

We quantified the size of polymeric PGN macromolecules by either flow cytometry or scanning electron microscopy (SEM). For nanoscale cytometry, we optimized light scatter voltages and detector thresholds for visualization of submicron events using a mixture of calibrated fluorescent nanobeads with median sizes ranging from $0.13 \mu \mathrm{m}$ to $1.35 \mu \mathrm{m}$ (Spherotech, Lake Forest, IL, USA). As reported by other investigators [35], side scatter (SSC) detection provided a better discrimination of submicron particles as compared to forward scatter (FSC), and we subsequently used median SSC quantification for sizing. We generated a "sizing" standard curve by plotting median SSC versus the size of calibrator nanobeads. The best fit polynomial curve (third order polynomial function, $\mathrm{R}^{2}=0.9998-1.0$ ) was subsequently used to interpolate the size of PGN particles. Data were acquired on LSRII (BD Biosciences, San Jose, CA, USA) or Cytek Aurora (Cytek Biosciences, Fremont, CA, USA) cytometers.

The size of PGN particles was confirmed by SEM. Biotinylated PGN or hkBa particles were deposited on streptavidin-coated Thermanox coverslips (Electron Microscopy Sciences, Hatfield, PA, USA) for $1 \mathrm{~h}$ at room temperature. Samples were fixed with a mixture of $2 \%$ paraformaldehyde and $2.5 \%$ glutaraldehyde in $0.1 \mathrm{M}$ sodium cacodylate buffer 
(pH 7.2), followed by 1.0\% osmium tetroxide in cacodylate. After stepwise dehydration through a discontinuous $30-100 \%$ ethanol gradient, specimens were chemically dried in hexamethyldisilazane for $5 \mathrm{~min}$, air dried in a desiccator for $30 \mathrm{~min}$ and sputter coated with gold using a Jeol DII-29010SCTR smart coater (Jeol USA Inc, Peabody, MA, USA). Coated specimens were viewed using a Jeol JCM-6000Plus scanning electron microscope under high vacuum and an accelerating voltage of $15 \mathrm{kV}$. Orthogonal axes (length and width) were measured within the acquisition software (JCM-6000Plus, Version 1.6.0) for at least 50 independent particles.

\subsection{Monocyte Internalization of FITC-Labeled PGN and/or hkBa}

For internalization studies, freshly isolated PBMCs were left untreated, mock-treated with DMSO or treated with endocytic inhibitors for $1 \mathrm{~h}$ at $37^{\circ} \mathrm{C}$ in a $5 \% \mathrm{CO}_{2}$ humidified atmosphere in the absence of serum. PBMCs were then chilled for $10 \mathrm{~min}$ on ice before the addition of FITC labeled particles, either PGN or hkBa pre-opsonized with pooled normal human serum. For cytometry analysis, a fluorescence minus one (FMO) reaction using unlabeled particles, either PGN or $\mathrm{hkBa}$, was run in parallel for each experimental condition. Internalization was allowed to proceed for $30 \mathrm{~min}$ at $37^{\circ} \mathrm{C}$ in a benchtop thermostated water bath, then stopped at endpoint by transferring cells to ice. PBMCs were subsequently stained on ice with PE-labeled anti-human CD14 and the Zombie Violet viability stain, the excess viability dye was quenched with $1 \%$ BSA and the cells were washed and resuspended in a known volume of HBSS. Two cytometry acquisitions were performed for each sample: an initial acquisition for $1 \mathrm{~min}$ before Trypan Blue (TB) quenching, followed by addition of one volume of $2 \%$ TB solution to quench surface fluorescence ( $30 \mathrm{~s}$ on ice) and acquisition of TB quenched samples for 2 min. For each run, TB's quenching coefficient was determined using surface FITC-labeled calibrator beads (Spherotech, Lake Forest, IL, USA) under the same acquisition protocol. Throughout the study, TB quenched the calibrator beads by roughly $90 \%$ (median $92.41 \%$, range $87.42-95.15 \%$ ). Data were acquired on a LSRII cytometer using BD FACSDiva software (Version 9.0; BD Biosciences, San Jose, CA, USA) and subsequently analyzed using FlowJo (version 10.8.1; FlowJo LLC, Ashland, OR, USA) and Prism (Version 9.3.1; GraphPad Software, San Diego, CA, USA).

During post-acquisition data processing, the frequency of phagocytic monocytes (FITC+CD14+), defined as CD14+ PBMCs that internalized FITC labeled particles, was assessed in FlowJo by gating above 99.5\% events of the paired FMO controls. To quantify the fluorescence intensity of internalized particles, we subtracted the expected residual surface signals from the experimentally observed fluorescence intensity after TB quenching. Assuming that TB quenches only the surface fluorescence, as observed using calibrator beads, with minimal to no internalization of the dye during the quenching step ( $30 \mathrm{~s}$ on ice before acquisition), then:

$$
\mathrm{MFI}_{\text {Internal }}=\left(\mathrm{MFI}_{\mathrm{TB}+}-\mathrm{K} \times \mathrm{MFI}_{\mathrm{TB}_{-}-}\right) /(1-\mathrm{K})
$$

where $\mathrm{MFI}_{\text {Internal }}$ represents the adjusted internalized fluorescence, $\mathrm{MFI}_{\mathrm{TB}-}$ and $\mathrm{MFI}_{\mathrm{TB}+}$ represent measured fluorescence intensities before and, respectively, after TB quenching, and $\mathrm{K}$ represents the residual quenched surface fluorescence assessed using calibrator beads $\left(\mathrm{K}=\right.$ bead $_{\mathrm{TB}+} /$ bead $\left._{\mathrm{TB}-}\right)$.

To reduce the variability between donors, paired normalization of particle uptake was performed by considering uptake by DMSO-treated PBMCs (mock challenge) as 100\% response, while unstimulated controls were set at 0 . When titrating the effect of latrunculin $\mathrm{B}$ on PGN uptake, a four-parameter logistic curve was fitted to normalized responses at increasing doses of latrunculin to estimate the relative $\mathrm{IC}_{50}$ and maximum effect of the inhibitor.

\subsection{Fluorescence Microscopy Analysis of FITC-PGN Uptake by Monocytes}

Freshly isolated PBMCs were seeded on poly-L-lysine coated glass coverslips in a 24well plate, and monocytes were allowed to adhere for $1 \mathrm{~h}$ in the absence of serum. PBMCs 
were pre-treated with either DMSO (mock challenge), latrunculin B or hydroxy-dynasore, both at $20 \mu \mathrm{M}$, for $1 \mathrm{~h}$ before addition of pre-opsonized PGN-FITC. Internalization of PGN-FITC progressed for $30 \mathrm{~min}$ at $37^{\circ} \mathrm{C}$, and was stopped by paraformaldehyde fixation ( $4 \%$ final concentration). Cells were washed, surface stained with a mixture of three biotinylated monoclonals anti-human CD14 (clones 61D3, Tuk4 and MEM-15, each at $2 \mu \mathrm{g} / \mathrm{mL}$ ) for $1 \mathrm{~h}$ at room temperature, permeabilized with saponin and stained for the lysosomal associated protein 1 (LAMP1) using a rabbit monoclonal antibody (clone 107, Novus Biologicals, $5 \mu \mathrm{g} / \mathrm{mL}$ ). Cells were washed and incubated with detection reagents, Cy3labeled streptavidin and Cy5-labeled donkey anti-rabbit IgG (Jackson ImmunoResearch, West Grove, PA, USA), fixed post-stain for 15 min with 4\% paraformaldehyde, counterstained with $5 \mu \mathrm{g} / \mathrm{mL}$ DAPI dilactate (Sigma, St. Louis, MO, USA) for $5 \mathrm{~min}$ at room temperature, washed and mounted in ProLong Gold (Life Technologies, Carlsbad, CA, USA). Mounted specimens were cured for at least $24 \mathrm{~h}$ at room temperature, protected from light, sealed and stored at $4^{\circ} \mathrm{C}$ until imaging.

Confocal images were acquired on a Nikon Ti2 inverted microscope (Nikon Instruments Inc., Melville, NY, USA) equipped with a four-laser excitation unit and a C2 Plus confocal scanning head using a Nikon Apo 60× NA 1.40 oil immersion objective. Z-stack images were collected at $0.5-\mu \mathrm{m}$ steps with confocal parameters selected to minimize the thickness of the calculated optical section using the NIS-Elements acquisition software (version 4.60, Nikon Instruments Inc., Melville, NY, USA). Post-acquisition, confocal datasets were processed in Imaris software (Version 9.5.1, Oxford Instruments, Concord, MA, USA) and presented as flattened maximum intensity projections of the z-stacks. The monocyte envelope was estimated by 3D rendering of CD14 staining in Imaris. For PGN/LAMP1 colocalization, z-stacks were segmented based on CD14 staining to limit analysis to cellassociated PGN. Individual PGN and LAMP1 signals were thresholded to eliminate background fluorescence and co-distribution of their respective staining was assessed in Imaris. A minimum of five independent z-stack datasets with at least 30 cumulative phagocytic monocytes were analyzed for each donor per experimental condition, and the mean LAMP1 colocalized volume as a fraction of total cellular PGN volume was used for comparisons between experimental groups.

\subsection{Flow Cytometry Analysis of Procoagulant and Proinflammatory Responses to PGN}

Freshly isolated PBMCs were left untreated, mock-treated with DMSO or treated with endocytic inhibitors in the absence of serum as above, then stimulated with $20 \mu \mathrm{g} / \mathrm{mL}$ pre-opsonized PGN in the presence of brefeldin $\mathrm{A}(3 \mu \mathrm{g} / \mathrm{mL})$ for $6 \mathrm{~h}$ at $37{ }^{\circ} \mathrm{C}$ in a humidified atmosphere containing $5 \% \mathrm{CO}_{2}$. After stimulation, cells were transferred to ice, stained for surface markers and viability (Zombie Aqua fixable viability stain, BioLegend, San Diego, CA, USA), fixed with $4 \%$ paraformaldehyde and stained for intracellular inducible antigens after saponin permeabilization. Dead cells were excluded based on viability stain positivity and monocytes were identified based on size, scatter and CD14 expression. Monocyte procoagulant responses were defined by tissue factor (TF/CD142) induction, while proinflammatory responses were defined by TNF. Data were collected on a LSRII cytometer using BD FACSDiva software (Version 9.0).

\subsection{Data Analysis and Representation}

Analysis of flow cytometry data and histogram overlays was performed in FlowJo (Version 10.8.1). Thresholds were set using either FMO (fluorescence minus one) controls for bacteria and PGN internalization, or isotype immunostaining run in parallel. Microscopy analysis was performed in Imaris software (Version 9.5.1). Polynomial curve fitting, interpolation of sizes from standard curves, normalizations and statistical analysis were all performed in Prism (Version 9.3.1). Differences between experimental groups were analyzed by repeated measures (RM) analysis of variance (ANOVA) with Geisser-Greenhouse correction for sphericity and Holm-Sidak's multiple comparisons test, unless otherwise noted. During latrunculin titration, the range of the inhibitor was extended from 20 to 
$40 \mu \mathrm{M}$ in 10 out of 14 donors analyzed. As a result, some pairwise comparisons had missing values and the dataset was analyzed by a mixed-effects, restricted maximum likelihood model with Geisser-Greenhouse and Holm-Sidak's corrections. For normalized data, we assessed significant deviations from the reference value of 100 set by the normalization process using one sample $t$ test. The threshold for statistical significance was set at $p<0.05$ and, unless detailed otherwise, adjusted $p$ values are conventionally represented across graphs $\left({ }^{*} p<0.05,{ }^{* *} p<0.01,{ }^{* * *} p<0.001,{ }^{* * * *} p<0.0001\right)$.

Individual donor responses along with median (dashed line), IQR (interquartile range, floating bars) and range (whiskers) are graphically depicted for either the frequency of responsive CD14+ monocytes (either phagocytic, TF+ or TNF+ monocytes) or the relative fluorescence intensity in CD14+ monocytes (individual values represent geometric mean of relative fluorescence intensities, gMFI). For comparisons of uptake between different particles (PGN vs. hkBa) or screening of multiple endocytic inhibitors, a summary representation depicting the mean \pm standard deviation was employed for clarity. Individual panels were generated with Prism (Version 9.3.1) except for histogram overlays (FlowJo, Version 10.8.1) and confocal micrographs (Imaris, Version 9.5.1), and figures were collated in Adobe Illustrator (Version 26.0.2, Adobe Inc., San Jose, CA, USA).

\section{Results}

\subsection{Sizing of PGN Macromolecules Purified from the Cell Wall of Bacillus Anthracis}

We previously reported that primary human innate immune cells efficiently recognize particulate bacterial PGN [10,11,33], and they internalize and process particulate PGN better than monomeric muramyl dipeptide (MDP) fragments [20,31]. Since the dimensions of the internalization cargo may limit the repertoire of endocytic pathways available for use, we estimated the size of polymeric peptidoglycan macromolecules purified from the bacterial cell wall of Bacillus anthracis by either calibrated nanoscale cytometry or scanning electron microscopy (SEM). For flow cytometry, we used calibrated nanobeads of known median size to optimize acquisition of submicron particles and generate a polynomial fit standard curve (third order polynomial function) from which PGN sizes were interpolated. As shown in Figure 1A,B, purified peptidoglycan polymers display broad sizes. While the median size among 17 independent anthrax PGN lots was similar $(0.265 \mu \mathrm{m}$ median, IQR $0.241-0.298 \mu \mathrm{m}$, range $0.228-0.339 \mu \mathrm{m})$, we observed higher variability for the largest $1 \%$ of PGN particles in these preps (median $0.784 \mu \mathrm{m}$, IQR $0.674-0.856 \mu \mathrm{m}$, range $0.552-0.896 \mu \mathrm{m}$ ). In a subset of four PGN preparations that were FITC-labeled to differentiate smaller particles from instrument noise during acquisition, the lower 1\% of PGN particles was below the lowest limit of quantitation defined by the smallest calibrator bead $(0.13 \mu \mathrm{m})$.

To test the accuracy of nanoscale flow cytometry estimates we measured the orthogonal axes of individual PGN particles after SEM imaging. SEM measurements of parental bacteria are shown for comparison (Figure 1C,D). As seen with flow cytometry, there was a wide distribution of sizes for PGN particles measured by SEM. While the overall length of PGN particles varied between 0.101 and $0.874 \mu \mathrm{m}$, the $0.268 \mu \mathrm{m}$ median length was in close agreement with the above estimates. The width of PGN particles varied between 0.070 and $0.623 \mu \mathrm{m}$, with a median of $0.205 \mu \mathrm{m}$. For comparison, the rod-shaped parental Bacillus anthracis strain Sterne BA781 displayed a $2.87 \mu \mathrm{m}$ median length (IQR 2.4-3.36 $\mu \mathrm{m}$, range 2.0-7.69 $\mu \mathrm{m}$ ) and $0.739 \mu \mathrm{m}$ width (IQR 0.697-0.799, range 0.594-0.887 $\mu \mathrm{m}$ ).

Overall, our data show a broad size range for anthrax PGN polymers within the bacterial cell wall, with a median of $0.265 \mu \mathrm{m}$. There is a good consistency between nanoscale flow cytometry estimates and the particle length observed by SEM, reflecting the accuracy of the method. These results indicate that PGN macromolecules released from the bacterial cell wall are similar or bigger than exosomes and extracellular vesicles released by mammalian cells, and their size could limit the endocytic pathways available for internalization by immune cells. 
A

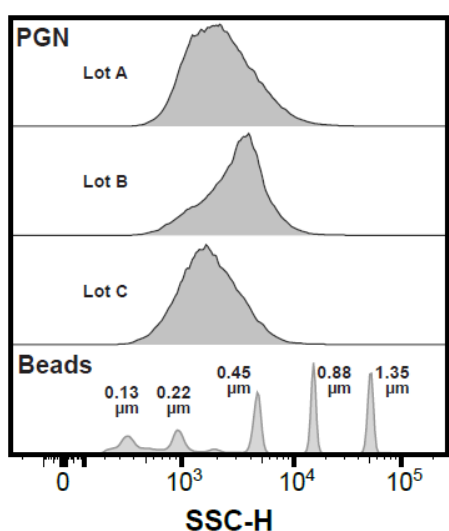

C.

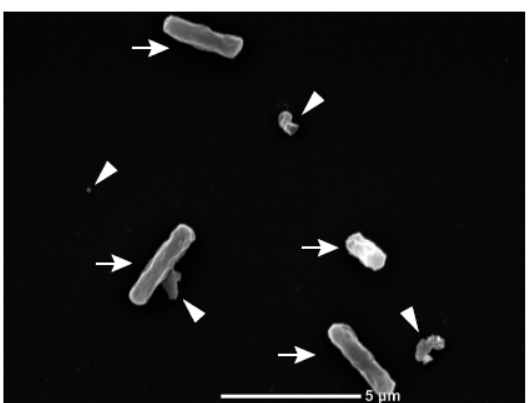

B.
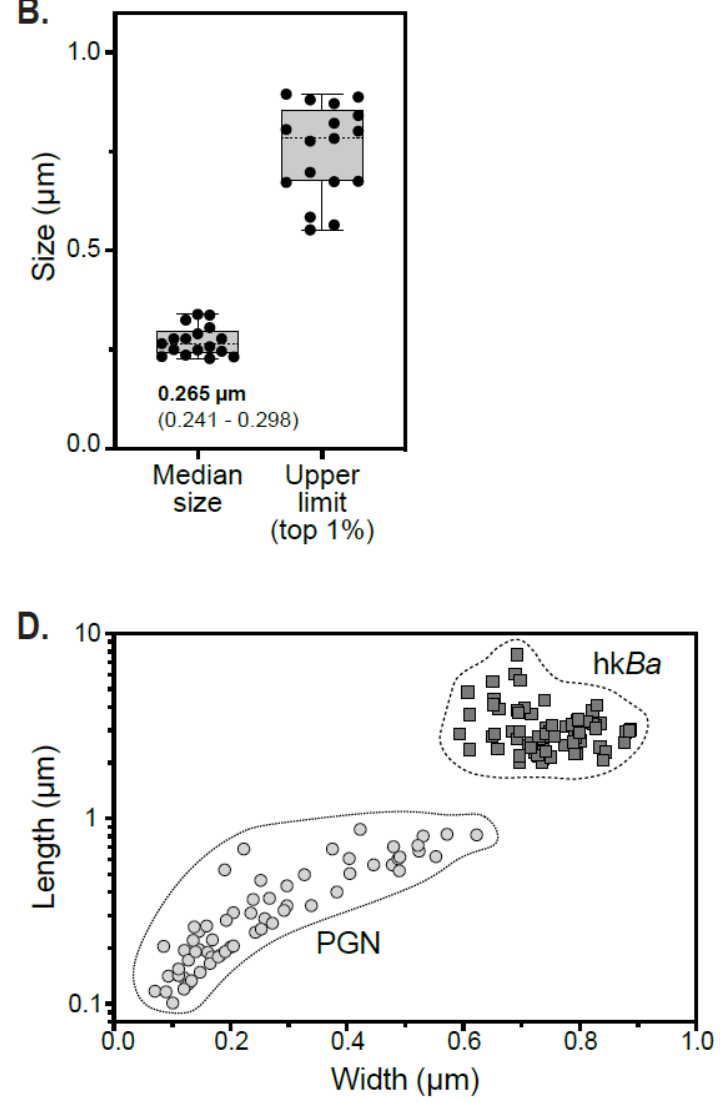

Figure 1. Size quantification of PGN macromolecules purified from the bacterial cell wall by nanoscale flow cytometry and scanning electron microscopy (SEM). (A) Histogram overlay of SSC measurements from 3 independent PGN lots depicting broad particle size distribution. For comparison, median SSC for nanobeads of known sizes used to calibrate the cytometry acquisition and generate the sizing standard curve is shown at the bottom. (B) Floating bar representation of sizes of PGN macromolecules from 17 independent purification lots depicting the median size (left) and the upper range (top 1\%, right) of PGN particles. The estimated median and interquartile range (IQR) of PGN particles is noted in the inset. The lower limit of PGN particles (not shown) was below the lower limit of quantitation (see details in text). (C) Scanning electron micrograph of PGN particles (arrowheads) and heat-killed Bacillus anthracis (arrows). (D) Distribution of PGN and Bacillus anthracis (hkBa) particles depicted based on orthogonal measurement of individual particles. For clarity, length is shown on a logarithmic scale while width is shown on a linear scale. Single lot, individual PGN particles ( $n=64$, circles) and hkBa ( $n=73$, squares) are shown.

\subsection{Pairwise Comparison of PGN and hkBa Internalization by Human Monocytes}

Given the dimensions of PGN macromolecules, we hypothesized that innate immune cells internalize PGN through phagocytosis, an endocytic process that critically requires reorganization of actin cytoskeleton. We therefore tested whether actin depolymerizing agents [36] block the internalization of PGN and/or hkBa by monocytes. Whilst we reported that immune responses to PGN are sensitive to cytochalasin D [8,32], preliminary internalization experiments indicated that latrunculins are more potent than cytochalasin $\mathrm{D}$, with latrunculin B slightly more potent than latrunculin A (data not shown). Latrunculin B was subsequently used as the actin depolymerizing agent for the rest of the study. As shown in Figure 2, latrunculin B reduced the internalization of PGN in a concentration dependent manner, albeit less than the inhibition of $\mathrm{hkBa}$ uptake. Incubation of PBMCs with PGN-FITC for $30 \mathrm{~min}$ at $37^{\circ} \mathrm{C}$ led to particle uptake by $43.9 \pm 9.1 \% \mathrm{CD} 14+$ monocytes (range $35-58.3 \%$ phagocytic monocytes; Figure $2 \mathrm{~B}$ ), which was significantly reduced to $27.5 \pm 5.3 \%$ in the presence of $5 \mu \mathrm{M}$ latrunculin B ( $p=0.001$, RM two-way ANOVA) and to $22.7 \pm 6.9 \%$ by 
$20 \mu \mathrm{M}$ latrunculin $(p=0.001)$. Similarly, the fluorescence intensity of internalized particles was reduced from 502.6 RFU (relative fluorescence units) in DMSO treated cells to $278.8 \mathrm{RFU}$ in PBMCs treated with $5 \mu \mathrm{M}(p=0.033)$ and $191.7 \mathrm{RFU}$ in the presence of $20 \mu \mathrm{M}$ latrunculin ( $p=0.033$; Figure 2C). Under similar conditions, monocytes internalized hkBa better, with $84.3 \pm 12.2 \%$ phagocytic monocytes observed on average (range $65.4-96.2 \%$ phagocytic monocytes) after $30 \mathrm{~min}$ in the absence of the inhibitor. Bacteria internalization was significantly reduced by latrunculin B (Figure 2B), both at $5 \mu \mathrm{M}(59.4 \pm 17.3 \%$, $p=0.0004$ compared to DMSO treatment) and $20 \mu \mathrm{M}$ inhibitor $(20.5 \pm 24.7 \%, p=0.0004)$. The intensity of internalized hkBa dropped from $5645 \pm 1735$ RFU in DMSO treated cells to $755 \pm 383 \mathrm{RFU}$ in $5 \mu \mathrm{M}$ latrunculin-treated $(p=0.002)$ and $62.5 \pm 52.6 \mathrm{RFU}(p=0.0015$ compared to DMSO treated cells) in the presence of $20 \mu \mathrm{M}$ inhibitor, with the latter not significantly different from background monocyte autofluorescence (39.5 $\pm 41.3 \mathrm{RFU})$. After normalization (Figure 2D), pairwise analysis of latrunculin inhibition suggests that hkBa uptake is more sensitive to latrunculin B than PGN uptake at both $5 \mu \mathrm{M}(85.1 \pm 9.0 \%$ reduction in $\mathrm{hkBa}$ uptake compared to $49 \pm 6.6 \%$ reduction in PGN, $p=0.0004$, RM ANOVA with Sidak's multicomparison correction) and $20 \mu \mathrm{M}$ inhibitor $(99.9 \pm 1 \%$ reduction in $\mathrm{hkBa}$ uptake compared to $65.3 \pm 12.5$ reduction in PGN, $p=0.0045)$. These data suggest that, while $\mathrm{hkBa}$ uptake is exclusively actin-dependent and effectively blocked by $20 \mu \mathrm{M}$ latrunculin B, monocytes internalize PGN preferentially, but not exclusively, through actin-dependent mechanisms.

\subsection{Actin-Dependent Mechanisms of PGN Uptake}

Since latrunculin B did not fully inhibit PGN uptake, we hypothesized that either (1) actin depolymerization may be incomplete but still sufficient to internalize smaller submicron particles as opposed to larger bacteria, or (2) PGN uptake may occur through actin-independent mechanisms. To test these possibilities, we modeled inhibition of PGN uptake after latrunculin titration over an extended concentration range $(0-40 \mu \mathrm{M})$ in a subset of 14 donors. As shown in Figure 3, latrunculin B did not fully block PGN internalization at any of the concentrations tested. Both the frequency of phagocytic monocytes (Figure 3B) and the intensity of internalized fluorescent particles (Figure 3C) were significantly reduced starting at $1 \mu \mathrm{M}$ inhibitor. At the highest concentration of latrunculin B tested, phagocytic monocytes were reduced by roughly $50 \%$ (28.3\% compared to $54.1 \%$ PGN+CD14+ monocytes in the absence of inhibitor; $p=0.0009$, mixed-effects model with Holm-Sidak's multicomparison correction) and the internalized fluorescence was reduced by $66 \%$ ( $557 \pm 361 \mathrm{RFU}$ compared to $1595 \pm 965 \mathrm{RFU}$ in the absence of inhibitor; $p=0.036$ ). After pairwise normalization to PGN uptake in control (DMSO) treated cells, latrunculin responses were fitted to a four-parameter logistic curve by least square regression (adjusted $\mathrm{R}^{2}=0.9981$ ). Mathematical modeling estimated a relative latrunculin $\mathrm{IC}_{50}$ of $1.93 \mu \mathrm{M}$ and plateauing of inhibition at $29.35 \%$, resulting in a maximum latrunculin-mediated inhibition of roughly $70 \%$ (Figure 3D). These data indicate that latrunculin B does not fully block the uptake of PGN particles, and actin-independent mechanisms could provide alternate internalization pathways.

Actin-depolymerizing agents, such as latrunculin, affect two main internalization pathways: phagocytosis and macropinocytosis. To assess the relative contribution of macropinocytosis to PGN internalization, we measured PGN uptake in the presence of amiloride, a macropinocytosis inhibitor. As shown in Figure 3E,F, PGN uptake was less sensitive to amiloride $(1 \mathrm{mM})$ than latrunculin B $(20 \mu \mathrm{M})$. Amiloride induced a small reduction in both the frequency of phagocytic monocytes (55.3\% compared to $63.1 \%$ in the absence of inhibitor; $p=0.0032$, RM ANOVA with Holm-Sidak's correction) and the fluorescence intensity of the internalized particles (1467 \pm 395 RFU compared to $2019 \pm 738$ RFU in the absence of inhibitor; $p=0.0413)$. Pairwise, latrunculin B was a more potent inhibitor than amiloride $(30.4 \%$ phagocytic monocytes, $p=0.0001$ compared to amiloride treatment and, respectively, $583 \pm 168$ RFU internalized MFI, $p=0.003$ compared 
to amiloride). These data indicate that PGN particles are primarily internalized through actin-dependent phagocytosis and not macropinocytosis.

A.

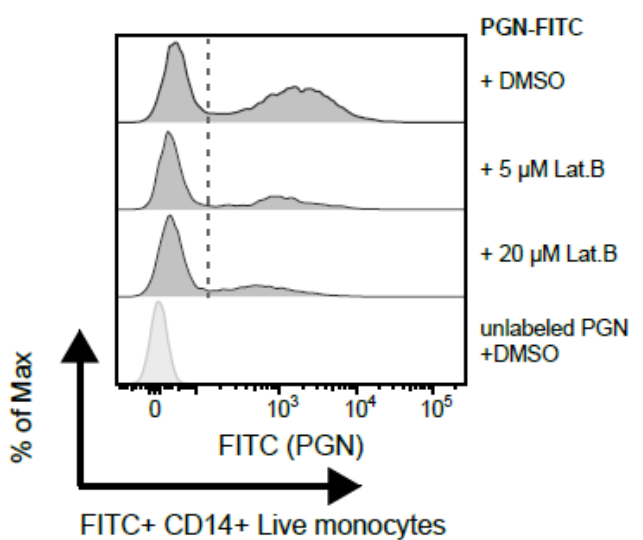

B.
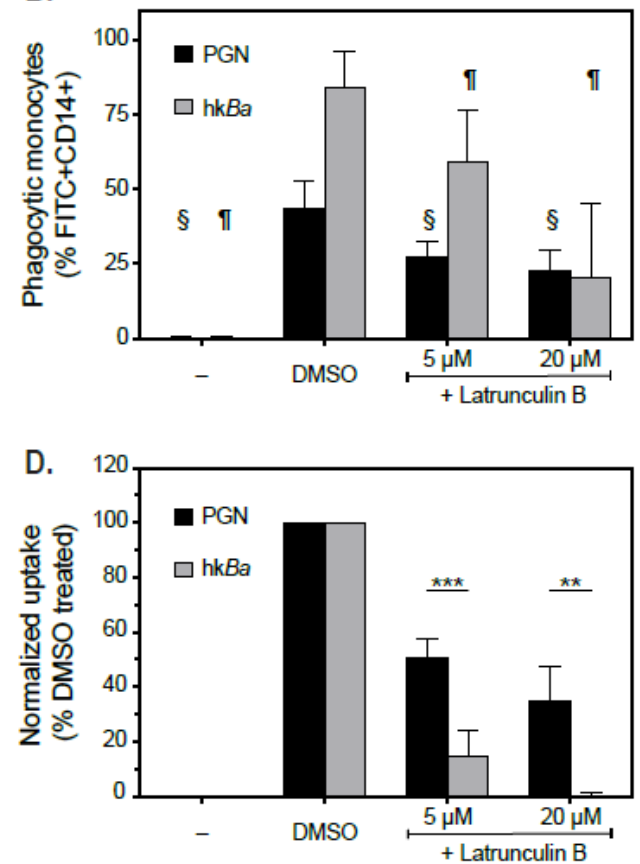
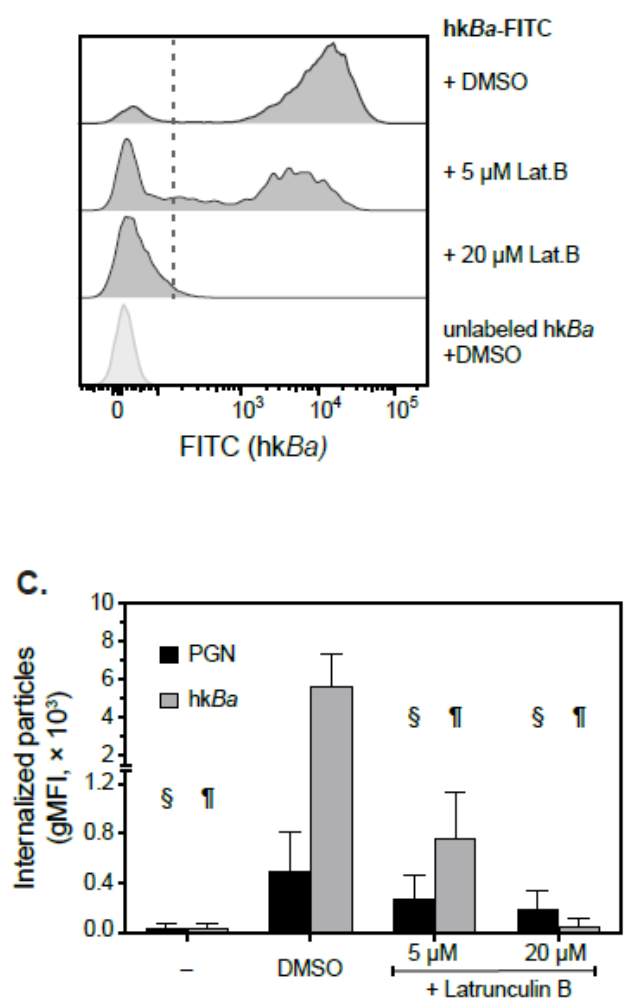

Figure 2. Comparison of latrunculin inhibition of PGN and hkBa internalization by primary human monocytes. (A) Representative histogram overlays of a median responsive individual depicting paired internalization of PGN-FITC (left) and hkBa-FITC (right) in CD14+ monocytes pretreated with DMSO (top) or either $5 \mu \mathrm{M}$ or $20 \mu \mathrm{M}$ latrunculin B (Lat.B). For comparison, the internalization of unlabeled PGN in DMSO-treated monocytes is shown in the bottom panel, while the threshold used to assess phagocytic cells is depicted graphically as a segmented line. (B,C) Summary representation of changes in monocyte internalization of FITC labeled particles, either PGN (black bars) or hkBa (grey bars), after latrunculin treatment. Data depict mean \pm standard deviation of phagocytic monocytes $(\%$ FITC + CD14+; (B)) or adjusted internalized fluorescence intensity (geometric mean fluorescence intensity, gMFI; (C)) of 6 independent experiments. Differences between groups were analyzed by repeated-measures two-way ANOVA with Holm-Sidak's multiple comparison correction (§ depicts significant changes, $p \leq 0.05$, compared to PGN-FITC internalization by DMSO-treated monocytes; II depicts significant changes, $p \leq 0.01$, compared to hkBa-FITC internalization by DMSO-treated monocytes). (D) Latrunculin effects on PGN and hkBa internalization after pairwise normalization to particle uptake in DMSO treated cells by the same donor. Statistically significant differences between latrunculin's effects on PGN vs. hkBa uptake are depicted conventionally $\left.{ }^{* *} p<0.01,{ }^{* * *} p<0.001\right)$. 
A.

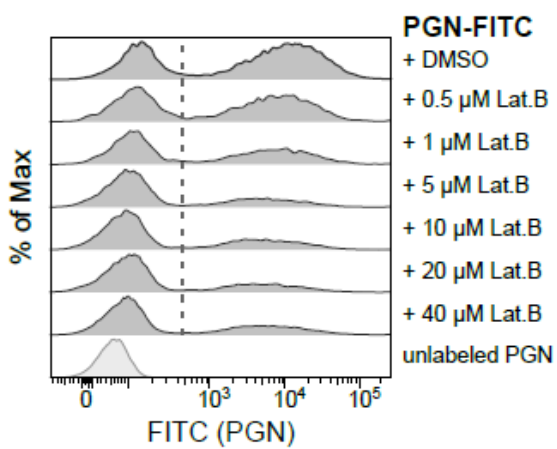

C.

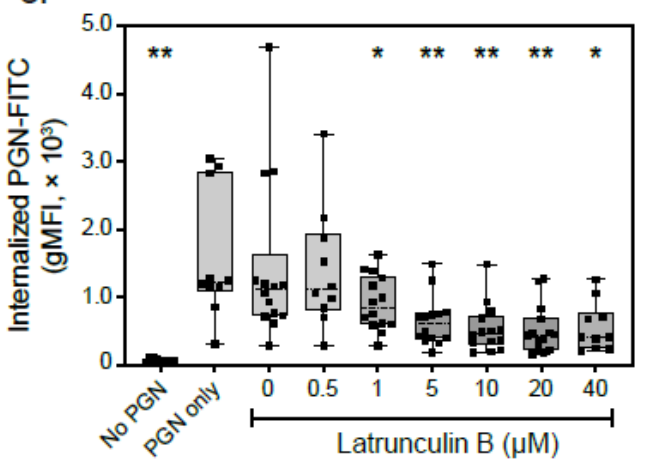

E.

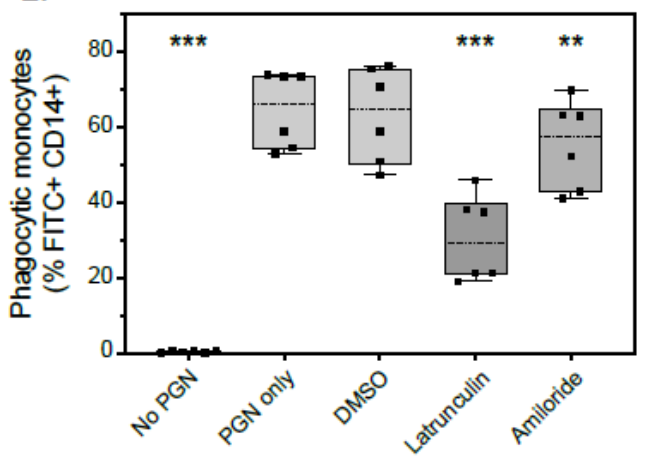

B.

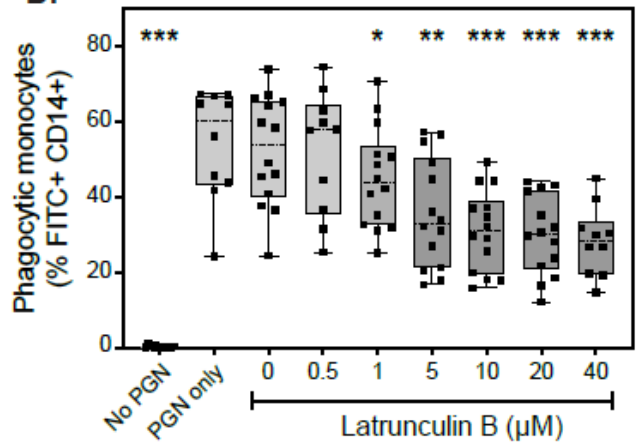

D.

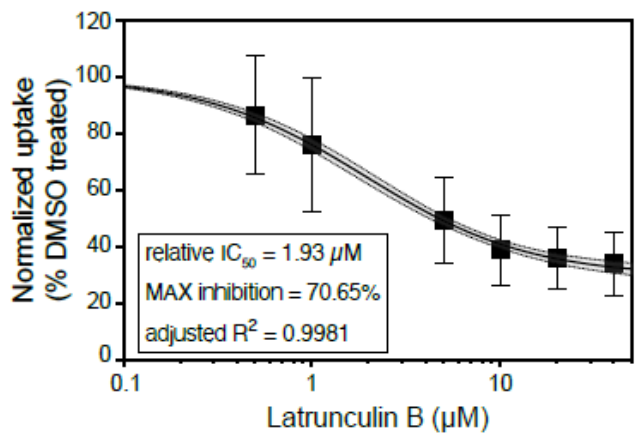

F.

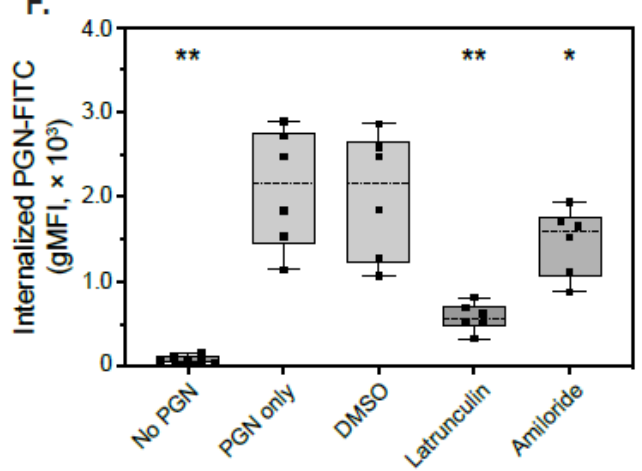

Figure 3. Monocyte uptake of PGN preferentially, but not exclusively, employs actin-dependent pathways. (A) Representative histogram overlay of a median responsive individual depicting titration of the latrunculin B inhibition of PGN uptake. For comparison, the internalization of unlabeled PGN in DMSO-treated monocytes is shown in the bottom panel, while the threshold used to assess phagocytic cells is depicted graphically as a segmented line. (B,C) Graphical representation of PGN uptake sensitivity to latrunculin B in 14 independent individuals, depicted as either phagocytic monocytes (B) or geometric mean of fluorescence intensity of internalized PGN-FITC particles (C). (D) Mathematical modelling of latrunculin B inhibition of PGN-FITC uptake. After pairwise normalization of PGN uptake, a four-parameter logistic curve (continuous line) was fitted by least square regression, and the relative $\mathrm{IC}_{50}$ and predicted maximum inhibition with latrunculin $\mathrm{B}$ were extracted from the model and shown in the inset. Dotted lines and shaded area depict the $95 \%$ confidence interval of the polynomial fit. (E,F) Pairwise comparison of PGN uptake sensitivity to latrunculin $B(20 \mu \mathrm{M})$ and the macropinocytosis inhibitor amiloride $(1 \mathrm{mM})$ in 6 independent donors, depicted as either phagocytic monocytes $(\mathbf{E})$ or geometric mean fluorescence intensity of internalized PGN-FITC particles (F). Statistically significant differences compared to PGN uptake in the absence of the inhibitor in panels $(\mathbf{B}, \mathbf{C}, \mathbf{E}, \mathbf{F})$ are depicted conventionally $\left({ }^{*} p<0.05,{ }^{* *} p<0.01,{ }^{* * *} p<0.001\right)$. 


\subsection{Actin-Independent Internalization of PGN Uptake}

To assess the contribution of actin-independent mechanisms to PGN uptake by primary human monocytes, we screened a panel of pharmacologic inhibitors of endocytic pathways, either individually or in combination with latrunculin inhibition (Figure 4). For this purpose, we tested inhibitors of clathrin (ES9-17 [37], $20 \mu \mathrm{M}$ ), dynamin (hydroxydynasore [38], $20 \mu \mathrm{M}$ ), RhoA (synergistic inhibitors Y16 and rhosin [39], $10 \mu \mathrm{M}$ each), Cdc42 (ML141 [40], $10 \mu \mathrm{M}$ ) and Arf6 (Secin H3 [41], $50 \mu \mathrm{M}$, and/or NAV 2729 [42], $10 \mu \mathrm{M}$ ), all of which contribute to overlapping repertoires of internalization pathways. When using single inhibitors, DMSO was added to maintain vehicle concentration constant.

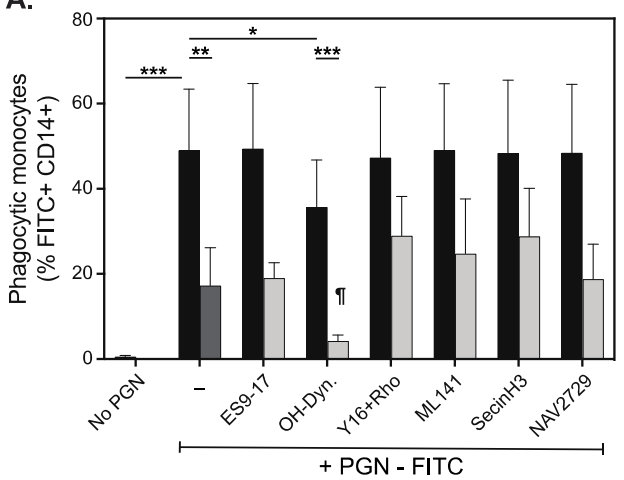

C.

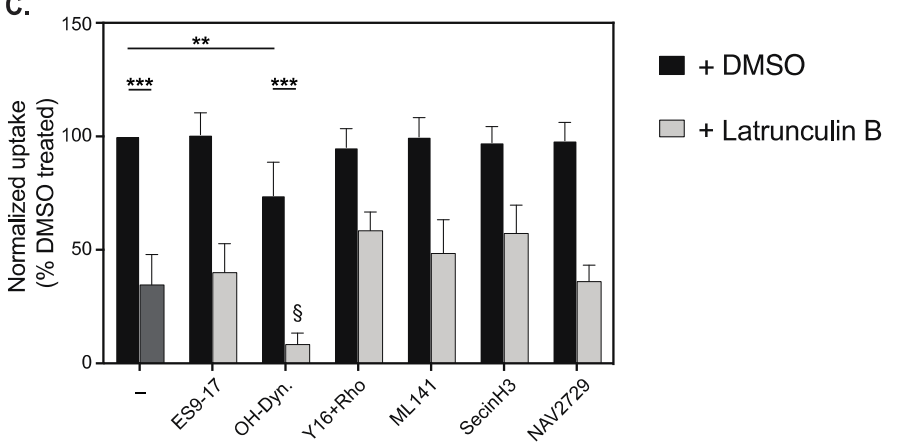

B.

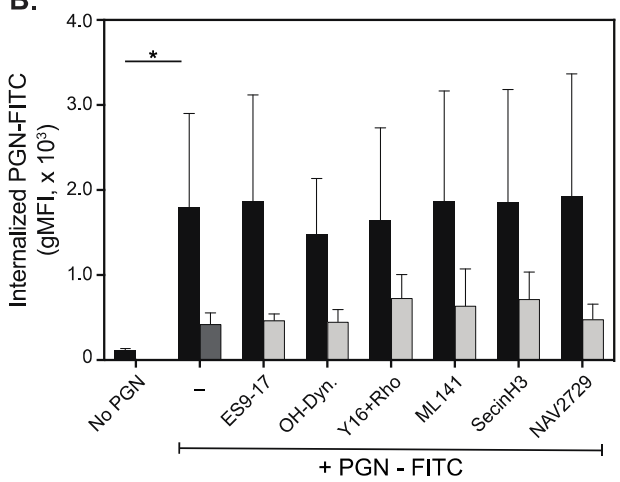

+ PGN - FITC

Figure 4. Actin-independent internalization of PGN particles by primary human monocytes. Summary representation (mean $\pm \mathrm{SD}, n=8$ ) of monocyte internalization of FITC labeled PGN in the presence of endocytic inhibitors, by themselves (black bars) or in combination with $20 \mu \mathrm{M}$ latrunculin $\mathrm{B}$ (light grey bars). The single inhibition with latrunculin is depicted as a dark grey bar in the absence of additional inhibitors. Panels depict frequency of phagocytic monocytes after 30 min incubation with PGN-FITC particles at $37^{\circ} \mathrm{C}$ (A), the adjusted fluorescence intensity of internalized particles (gMFI, (B)) and the relative effect of inhibitors after pairwise normalization to uptake in mock (DMSO) treated cells $(\mathbf{C})$. Statistically significant differences between relevant groups are depicted conventionally $\left(^{*} p<0.05,{ }^{* *} p<0.01,{ }^{* * *} p<0.001\right)$, except for panel $(\mathbf{A}, \mathbf{C})$, where $\mathbb{I}(p=0.0363)$ and $\S(p=0.0074)$ depict significant changes when the combined latrunculin $\mathrm{B}$ and hydroxy-dynasore treatment is compared to latrunculin alone.

As seen in Figure 4, hydroxy-dynasore (OH-Dyn.) was the only pharmacological agent that reduced PGN-FITC uptake in this panel, either by itself or in combination with latrunculin B. Hydroxy-dynasore reduced the frequency of phagocytic monocytes after $30 \mathrm{~min}$ incubation with PGN-FITC at $37^{\circ} \mathrm{C}$, from $49.1 \pm 14.4 \%$ in control-treated cells to $35.7 \pm 11.1 \%$ ( $p=0.0452$, RM ANOVA with Holm-Sidak's multicomparison correction (Figure 4A). The effect was less pronounced than latrunculin, which reduced phagocytic monocytes to $17.2 \pm 8.9 \%$ ( $p=0.0021$ compared to DMSO treatment) in these donors. The combined treatment with latrunculin and hydroxy-dynasore provided the strongest reduction in phagocytic monocytes, to $4.2 \pm 1.4 \%$ ( $p=0.0008$ compared to OH-Dyn alone, and $p=0.0363$ 
compared to latrunculin B treatment). However, the hydroxy-dynasore mediated reduction in fluorescence intensity of internalized particles (Figure 4B), from $1799 \pm 1100 \mathrm{RFU}$ in DMSO-treated cells to $1471 \pm 664$ RFU, did not pass the statistical threshold. After pairwise normalization to decrease variability between donors (Figure 4C), hydroxy-dynasore inhibition accounted for a $26.1 \%$ reduction of PGN-FITC uptake $(p=0.0093)$, while latrunculin $\mathrm{B}$ reduced it by $65.4 \%(p<0.0001)$. Overall, actin and dynamin dependent internalizations support virtually all PGN uptake, as combined inhibition with latrunculin and hydroxydynasore reduces uptake by roughly $90 \%$.

\subsection{Phagolysosomal Trafficking of Internalized PGN}

Lysosomal processing of polymeric bacterial PGN is needed to release signalingactive subunits responsible for immune activation [20]. Since different internalization pathways may direct cargo to distinct endocytic compartments, we investigated whether actin- and/or dynamin-mediated internalization affect the phagolysosomal targeting of PGN. Freshly isolated PBMCs were seeded on poly-L-lysine coated coverslips to allow monocyte attachment, pre-treated with DMSO (vehicle), latrunculin or hydroxy-dynasore in the absence of serum for $1 \mathrm{~h}$, incubated with PGN-FITC particles for $30 \mathrm{~min}$ at $37^{\circ} \mathrm{C}$, then fixed and processed for immunofluorescence microscopy. The phagolysosomal progression of monocyte-associated PGN particles was assessed by colocalization with the lysosomal marker LAMP1/CD107a (lysosomal-associated membrane protein 1). As shown in Figure 5, fluorescent PGN particles associated with monocytes under all experimental conditions tested, although, as previously quantified by flow cytometry, the number of phagocytic cells was reduced in the presence of either inhibitor. CD14 staining coalesced around PGN particles in line with CD14 recognition of PGN carbohydrates [43]. PGN internalization for $30 \mathrm{~min}$ at $37^{\circ} \mathrm{C}$ led to phagolysosomal targeting of PGN, with roughly $40 \%$ of cell associated PGN-FITC particles colocalizing with LAMP1 in the absence of inhibitors (median 37.8\%, IQR 34.2-46.4\%, range 31.6-59.5\%). Inhibition of actin-polymerization by latrunculin reduced PGN phagocytosis and slowed down phagolysosomal trafficking of cell associated PGN, with only 13\% PGN-FITC particles colocalizing with LAMP1 after 30 min (median $12.99 \%$, IQR 11.2-14.3\%, range 4.6-21.1\%; $p=0.0002$ compared to DMSO-treated cells). Similar to the flow cytometry studies above, dynamin inhibition had a smaller effect on PGN-LAMP1 colocalization (median 27.8\%, IQR 23.2-34.9\%, range 17.7-34.9\%; $p=0.0037$ compared to DMSO-treated cells and, respectively, $p=0.0017$ compared to latrunculin treatment). From these studies, we conclude that PGN internalization through actindependent phagocytosis supports faster targeting of PGN for lysosomal degradation. Dynamin-internalized PGN endosomes, which become predominant in latrunculin treated cells, either recruit lysosomes more slowly or they are directed towards other endocytic compartments, leading to decreased colocalization with LAMP1 in these timed experiments.

\subsection{Effect of Endocytic Inhibitors on Immune Responses to PGN}

Since latrunculin and hydroxy-dynasore reduced the uptake and intracellular trafficking of PGN particles, we hypothesized they would subsequently affect immune responses to PGN which primarily occur downstream of lysosomal processing. We tested this hypothesis by quantifying monocyte procoagulant and proinflammatory responses after stimulation with $20 \mu \mathrm{g} / \mathrm{mL}$ PGN for $6 \mathrm{~h}$ in the presence of brefeldin A to block the cytokine-mediated feedback amplification [32]. In line with this model, latrunculin B and, to a lesser extent, hydroxy-dynasore, reduced both tissue factor (TF) and TNF induction post-challenge (Figure 6). 
A.

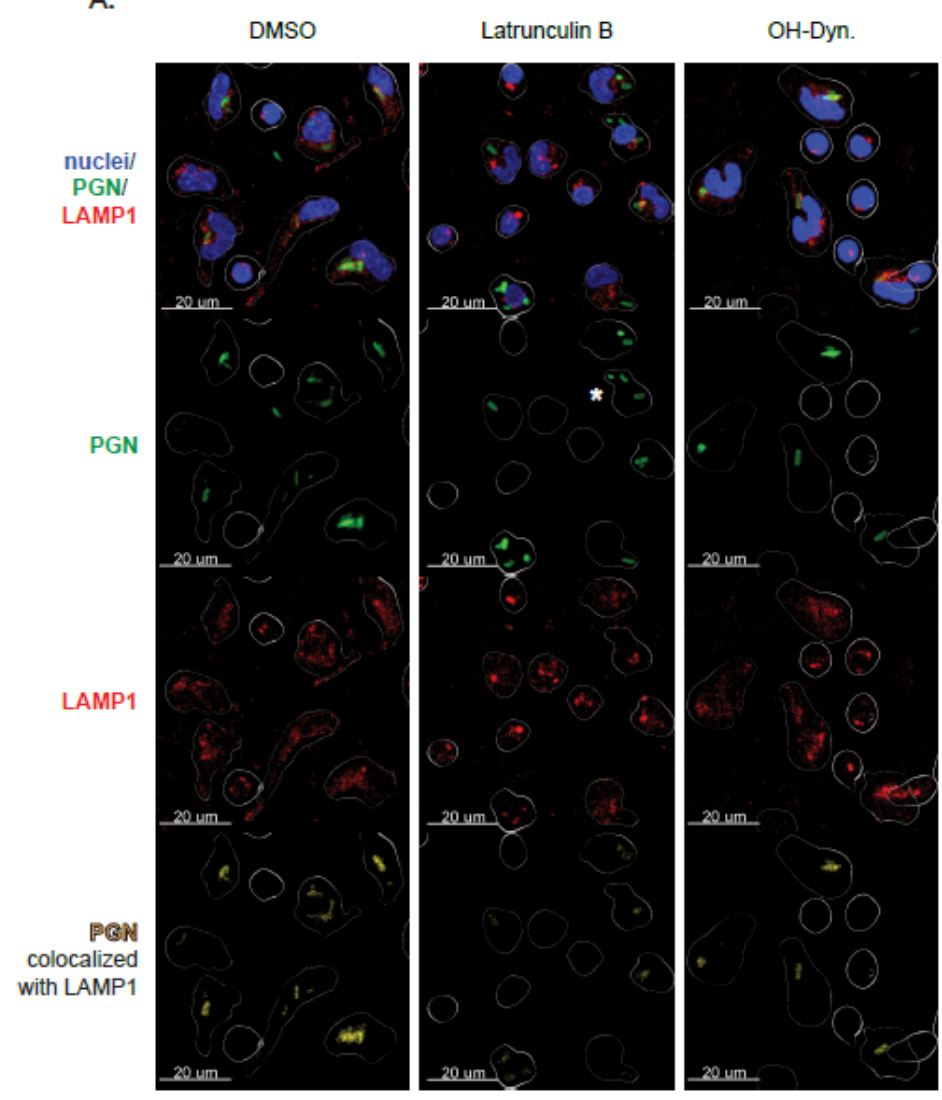

B.

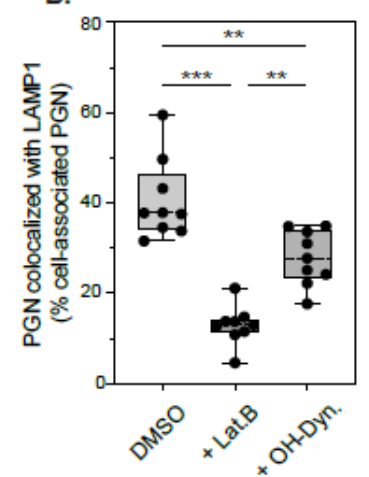

Figure 5. Phagolysosomal trafficking of PGN after inhibition of actin and/or dynamin-dependent internalization. (A) Representative confocal micrographs depicting phagolysosomal trafficking of PGN-FITC in a median responsive individual in the absence (left column) or presence of internalization inhibitors (middle and right columns). Top row illustrates maximum intensity projections of confocal z-stacks showing PGN (green), LAMP1 (red) and cell nuclei (blue). Middle rows depict individual PGN (green) and LAMP1 (red) signals in monocytes, while the bottom row shows cell associated PGN that colocalizes with LAMP1 (yellow). In all panels, the monocyte envelope was projected by 3D rendering of CD14 staining using Imaris and is depicted as an intermittent white line to highlight cellular regions. The colocalization signals were generated in Imaris based on the co-distribution of individual PGN and LAMP1 signals in z-stack datasets. Note the reduction in colocalization signals (bottom panels), primarily in latrunculin-treated cells. Internalized PGNs with no associated LAMP1 were consistently observed in latrunculin-treated cells and are highlighted ${ }^{*}$ ) in the middle panel. (B) Graphical representation of latrunculin- and dynasore-induced changes in PGN-LAMP1 colocalization in monocytes isolated from 9 independent donors. Individual responses represent the mean volume of cell-associated PGN that colocalizes with LAMP1 from 5 independent confocal z-stacks per donor. Statistically significant differences between experimental groups are depicted conventionally $\left.{ }^{* *} p<0.01, * * * p<0.001\right)$ 
A.

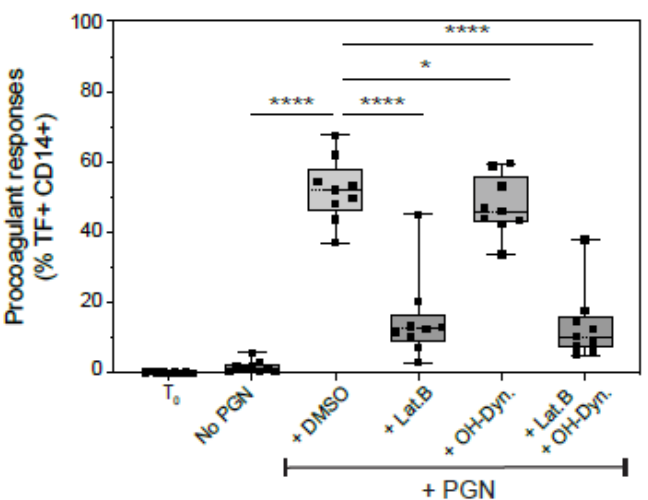

C.

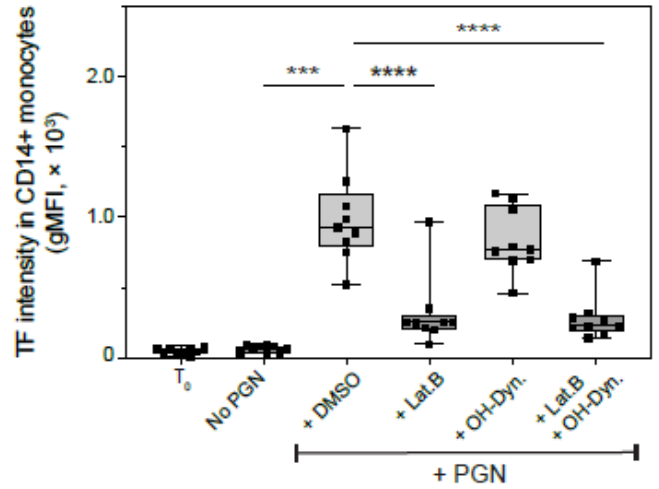

E.

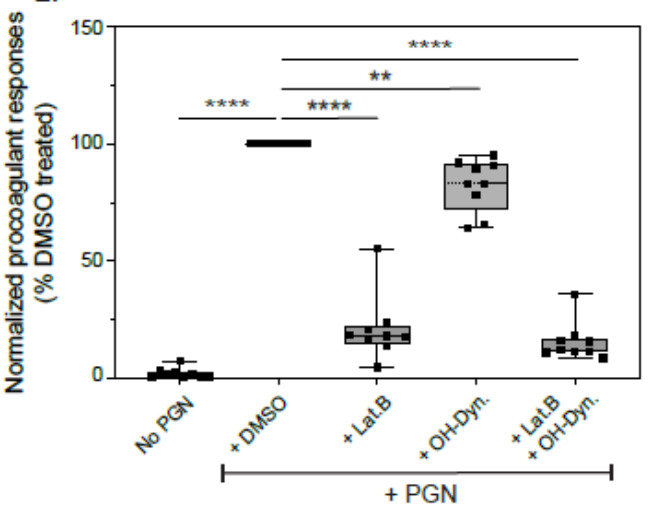

B.

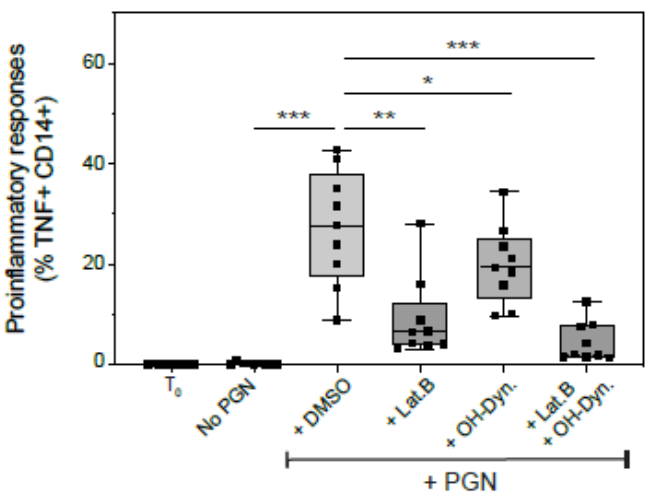

D.
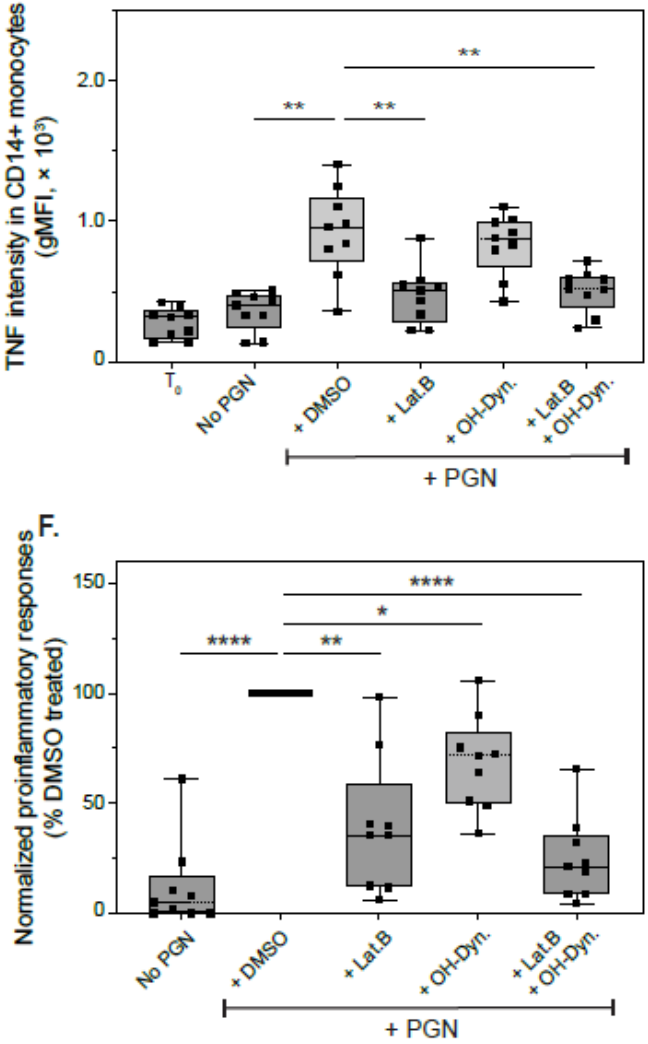

Figure 6. Modulation of immune responses to PGN after inhibition of actin and/or dynamindependent internalizations. Primary human PBMCs were mock-treated (DMSO) or treated with latrunculin B (Lat.B) or hydroxy-dynasore (OH-Dyn.) for $1 \mathrm{~h}$, followed by $6 \mathrm{~h}$ stimulation with PGN $(20 \mu \mathrm{g} / \mathrm{mL})$ in the presence of brefeldin A. Inducible expressions of TF $(\mathbf{A}, \mathbf{C}, \mathbf{E})$ or TNF $(\mathbf{B}, \mathbf{D}, \mathbf{F})$ were assessed by flow cytometry after comparison with a paired unstimulated aliquot fixed at the start of the experiment $\left(\mathrm{T}_{0}\right)$. Data depict frequency of responsive monocytes $(\mathbf{A}, \mathbf{B})$, the geometric mean of fluorescence intensity of inducible antigens $(\mathbf{C}, \mathbf{D})$ and normalized induction of TF and TNF $(\mathbf{E}, \mathbf{F})$ after pairwise normalization to DMSO-treated cells $(n=9)$. Statistically significant differences compared to PGN responses in the absence of the inhibitors (DMSO-treated cells) are depicted conventionally ${ }^{*} p<0.05,{ }^{* *} p<0.01,{ }^{* * *} p<0.001,{ }^{* * * *} p<0.0001$; RM ANOVA with Holm-Sidak's multicomparisons test).

As illustrated in Figure 6A, the frequency of procoagulant monocytes, defined as $\mathrm{TF}+\mathrm{CD} 14+$, was significantly reduced by latrunculin B from 52\% (IQR 45.9-58.2\%, range $37.1-67.6 \%$ ), in mock treated cells, to $12.5 \%$ (IQR $8.8-16.8 \%$, range $3-45.1 \%$; $p<0.0001$ RM ANOVA with Holm-Sidak's post test). Similarly, the intensity of TF signal in monocytes decreased from 928 RFU (IQR 786-1167 RFU, range 523-1632 RFU) to 253 RFU 
(IQR 205-304 RFU, range 96-965 RFU; $p<0.0001)$. Inhibition of dynamin-dependent internalization had a smaller effect on PGN-induced procoagulant responses and reduced the frequency of TF+CD14+ monocytes to $45.9 \%$ (IQR $42.9-56 \%$, range $33.6-59.6 \%$; $p=0.0167$ ). The small reduction in monocyte TF intensity (median 769, IQR 695-1093 RFU, range 460-1170) approached, but did not pass, the significance threshold ( $p=0.0579$ compared to DMSO treatment). After pairwise normalization to immune responses in control treated cells (Figure 6E), hydroxy-dynasore reduced TF induction by $17.6 \%(p=0.0053$ ), while latrunculin reduced TF by 79.1\% ( $p<0.0001)$. These results closely resemble the effects of the inhibitors on PGN uptake and indicate that procoagulant responses to PGN are internalization-dependent. The combined treatment with both latrunculin B and hydroxydynasore inhibited TF induction the most ( $85 \%$ reduction; $p=0.0398$ when compared to latrunculin alone, and $p<0.0001$ compared with either OH-Dyn and/or DMSO treatment).

Modulation of monocyte proinflammatory responses, defined by TNF expression, mimicked changes observed for procoagulant responses (Figure 6B,D,F). TNF induction, however, displayed a higher degree of variability between individual donors compared to procoagulant responses. Interestingly, after normalization (Figure 6F), dynasore-inhibition of TNF was more pronounced than TF reduction, resulting in a $31.5 \%$ inhibition of TNF ( $p=0.0112$ compared to control treatment), while concomitantly latrunculin reduction of TNF was smaller than that observed for TF: $60.3 \%$ compared to $79.1 \%$, respectively. Due to the higher variability in TNF responses between donors, the TNF reduction observed with the combined latrunculin and dynasore treatment $(75.4 \%)$ was not significantly different than from latrunculin alone $(p=0.066)$. Overall, our results confirm that immune responses to PGN primarily occur following internalization and lysosomal processing, since combined latrunculin and dynasore inhibition reduced proinflammatory and procoagulant responses by $75-85 \%$. Interestingly, the reduction in frequency of activated monocyte after hydroxydynasore, in both longer activity assays and shorter timed uptake experiments, seem to indicate that at least a subset of monocytes exclusively utilizes the dynamin pathway to take up this PAMP.

\section{Discussion}

Systemic anthrax is characterized by high bacteremia [44], which leads to an increased burden of both pathogen and pathogen-derived PAMPs. While virulence factors such as the bipartite anthrax toxins contribute to disease progression and pathology, other non-toxigenic PAMPs support clinical anthrax manifestations [45-47]. We and others have identified cell wall peptidoglycan (PGN) as a major PAMP supporting septic anthrax pathology $[12,16,48]$. Anthrax peptidoglycan triggers proinflammatory responses in primary human monocytes, neutrophils [20,32,34,49] and in non-human primates in vivo [12,16], primarily through activation of intracellular NOD receptors [31]. Thus, efficient immune responses to PGN require internalization and lysosomal processing of the macromolecule within phagocytes. Peripheral blood leukocytes, primarily monocytes and neutrophils, respond better to particulate anthrax PGN than MDP [31], which, in part, may be due to better recognition and uptake of the polymeric PGN macromolecule than its hydrolyzed monomers. We are unaware of reports describing the mechanisms of anthrax PGN internalization in primary human innate immune cells until now; however, immune responses to particulate PGN were sensitive to cytochalasin D [8,11,20,32], indicative of actin-mediated internalization. Likewise, latrunculin B in this study inhibited most of the uptake and subsequent immune responses to PGN. Extensive titration and modelling of latrunculinmediated inhibition revealed that, even at high doses, $10-20 \times \mathrm{IC}_{50}$, there is a significant, roughly $30 \%$, actin-independent uptake of PGN. We subsequently show this pathway to be dynamin-dependent. The dynamin pathway was not triggered because of the phagocytic blockade since the dynamin inhibitor reduced PGN uptake in the absence of any other inhibitor.

Reorganization of the cortical actin cytoskeleton is a critical early step in both immunereceptor mediated phagocytosis [2] and macropinocytosis [3], the nonspecific uptake 
of large volumes of extracellular fluid. Macropinocytosis has been shown to support macrophage uptake of MDP [50] as well as the internalization of bacterial cell wall by epithelial cells [51]. In the current study, latrunculin was a more potent inhibitor of PGN uptake than amiloride, a selective inhibitor of macropinocytosis which also inhibits dynamindependent fast endophilin-mediated endocytosis (FEME) [52]. In pairwise comparisons, PGN uptake was 3.25-fold more sensitive to latrunculin than to amiloride (range $1.9 \times-4.6 \times$ in individual donors). The small amiloride effect most likely depicts involvement of constitutive macropinocytosis, FEME or a combination of the two. Overall, our data support a model of phagocytic internalization of PGN as the main actin-dependent internalization pathway in primary human monocytes.

Our current observations together with previous reports detailing PGN opsonization requirements $[10,11,33]$, engagement of Fc receptors $[10,49]$ and sensitivity to Syk and Src inhibitors [11,32] indicate that polymeric PGN uptake occurs primarily, but not exclusively, through Fc or complement receptor (CR) mediated phagocytosis. While similar overall, molecular differences between these two pathways have been reported [2]. The tyrosine kinase Syk has been implicated in both pathways [53,54], and immune responses to PGN are sensitive to Syk inhibitors [11]. In canonical models, FcR phagocytosis promotes actin reorganization through Cdc42 and Rac small GTPases, while CR-phagocytosis utilizes RhoA [55]. Surprisingly, neither Cdc42 inhibition nor RhoA inhibition affected PGN uptake in our study. It is possible that canonical phagocytic models developed with differentiated immune cells might not fully translate to primary naïve human cells used here. Redundant activities for Src family kinases during FcR-mediated phagocytosis have been reported [56] and, likewise, it is possible that other small GTPases, such as Rac, could overcome Cdc42 or RhoA inhibition in our study. As such, molecular details of PGN-triggered phagocytic uptake will require further study.

In general, cells internalize larger particles through actin-mediated uptake, either macropinocytosis or phagocytosis, while smaller cargo can enter through clathrin coated pits, caveolae or similar endocytic structures. The broad size of PGN macromolecules measured in this study, ranging from 100 to $874 \mathrm{~nm}$, indicates that there are no biophysical sizing restrictions that will impede PGN uptake by any of these pathways. Unlike MDP [24] or anthrax toxins [57] that internalize through CME, PGN uptake was clathrin-independent and insensitive to either ES9-17 (shown) or pitstop2 (not shown). We therefore analyzed PGN internalization by clathrin-independent endocytosis (CIE) using a simplified overview detailed by Mayor and Pagano [4]. Accordingly, CIE can be split into dynamin-dependent and independent pathways. The dynamin-dependent CIE can be further divided into caveolin- and/or RhoA-dependent internalizations, while dynamin-independent pathways can be grouped into Cdc42- or Arf6-dependent internalizations. We used an overlapping panel of pharmacologic inhibitors for most of these pathways, except caveolin, for which there is no specific pharmacologic inhibitor reported to date. Our data show that in primary human monocytes, the alternate CIE uptake is dynamin-dependent but independent of RhoA, Cdc42 and Arf6 GTPases.

The identity of the dynamin-dependent CIE is currently elusive, but multiple lines of evidence point to a caveolar uptake of PGN. Caveolin is expressed in myeloid cells [58] and attaches to lipid microdomains enriched in cholesterol, glycosphingolipids and glycosylphosphatidylinositol (GPI)-anchored proteins (GPI-AP), forming flask shaped invaginations named caveolae. Non-opsonic caveolar uptake of bacteria, mediated by GPI-anchored receptors, has been documented and promotes phagolysosomal escape [59]. Similarly, the dynamin-dependent PGN uptake, emphasized after latrunculin inhibition, displays lower lysosomal PGN localization. Interestingly, two putative PGN receptors, CR3 and CD14, can associate with caveolae [58]. Although CR3 could mediate GPI-AP uptake in the absence of serum opsonization, in the presence of serum, it likely supports phagocytic internalization [60]. The caveolar uptake of polymeric PGN seems more likely dependent on CD14, a GPI-anchored protein itself. Although CD14 interaction with polymeric PGN has been documented [43], the mechanisms underlying CD14's role in cellular responses to 
PGN are unresolved. In our study, monocyte CD14 staining coalesced in the presence of PGN particles, which could represent aggregation in GPI-AP microdomains, which, in turn, could promote caveolar organization and trafficking. Furthermore, Src phosphorylation of caveolin-1 is needed for caveolae scission [61], and we previously reported reduced PGN responses in the presence of Src inhibitors [11]. It is worth reiterating that Src kinases are also involved in FcR-mediated phagocytosis (see above) and, by themselves, these inhibitors cannot differentiate between these two endocytic pathways. Overall, while the propensity of evidence indicates caveolar PGN uptake as the dynamin-dependent CIE, further studies are needed to define this pathway at the molecular level. Regardless, the actin-insensitive uptake of PGN displayed inefficient phagolysosomal trafficking and, consequently, lowered proinflammatory and procoagulant responses in primary monocyte. Whether or not this pathway is selectively enhanced during bacterial infection resulting in attenuated immune reactions to bacteria and/or peptidoglycan remains to be established.

\section{Conclusions}

In this study, we show that particulate PGN polymers isolated from Bacillus anthracis display broad sizes and are internalized through multiple endocytic pathways. Pharmacological screening shows that naïve human monocytes primarily internalize particulate PGN by actin-mediated phagocytosis. To a lesser extent, PGN is internalized by an alternate dynamin-dependent pathway which does not require clathrin, RhoA, Cdc42 or Arf. Actin-mediated internalization supports faster phagolysosomal targeting of PGN than the dynamin pathway and subsequent procoagulant and proinflammatory responses in primary human monocytes.

Author Contributions: Conceptualization, N.I.P. and K.M.C.; Data curation, N.I.P.; Formal analysis, N.I.P.; Funding acquisition, K.M.C.; Investigation, N.I.P., J.C., E.D., J.K. and R.S.; Methodology, N.I.P. and R.S.; Project administration, N.I.P.; Supervision, N.I.P. and K.M.C.; Visualization, N.I.P.; Writing—original draft, N.I.P.; Writing—review and editing, N.I.P. and K.M.C. All authors have read and agreed to the published version of the manuscript.

Funding: This research was funded by the National Institute of Allergy and Infectious Diseases, grant U19AI062629 (K.M.C).

Institutional Review Board Statement: Not applicable.

Informed Consent Statement: Not applicable.

Data Availability Statement: All study data used to generate figures are included in the report, except for the summary bar graph representations as detailed in the Materials and Methods Section. Excel datasets used for these figures are available upon request from the corresponding author (narcis-popescu@omrf.org).

Acknowledgments: We are thankful to all volunteers who enrolled in this study and the Flow Cytometry Core at OMRF for assistance with nanoscale cytometry assays.

Conflicts of Interest: The authors declare no conflict of interest relevant to the study. The funders had no role in the design of the study; in the collection, analyses, or interpretation of data; in the writing of the manuscript, or in the decision to publish the results.

\section{References}

1. Lin, A.E.; Guttman, J.A. Hijacking the endocytic machinery by microbial pathogens. Protoplasma 2010, 244, 75-90. [CrossRef]

2. Flannagan, R.S.; Jaumouille, V.; Grinstein, S. The cell biology of phagocytosis. Annu. Rev. Pathol. 2012, 7, 61-98. [CrossRef] [PubMed]

3. Lin, X.P.; Mintern, J.D.; Gleeson, P.A. Macropinocytosis in Different Cell Types: Similarities and Differences. Membranes Basel 2020, 10, 177. [CrossRef] [PubMed]

4. Mayor, S.; Pagano, R.E. Pathways of clathrin-independent endocytosis. Nat. Rev. Mol. Cell Biol. 2007, 8, 603-612. [CrossRef] [PubMed]

5. Harper, C.B.; Popoff, M.R.; McCluskey, A.; Robinson, P.J.; Meunier, F.A. Targeting membrane trafficking in infection prophylaxis: Dynamin inhibitors. Trends Cell Biol. 2013, 23, 90-101. [CrossRef] [PubMed] 
6. Vollmer, W.; Blanot, D.; De Pedro, M.A. Peptidoglycan structure and architecture. FEMS Microbiol. Rev. 2008, 32, 149-167. [CrossRef] [PubMed]

7. Wolf, A.J.; Reyes, C.N.; Liang, W.; Becker, C.; Shimada, K.; Wheeler, M.L.; Cho, H.C.; Popescu, N.I.; Coggeshall, K.M.; Arditi, M.; et al. Hexokinase Is an Innate Immune Receptor for the Detection of Bacterial Peptidoglycan. Cell 2016, 166, 624-636. [CrossRef]

8. $\quad$ Langer, M.; Girton, A.W.; Popescu, N.I.; Burgett, T.; Metcalf, J.P.; Coggeshall, K.M. Neither Lys- and DAP-type peptidoglycans stimulate mouse or human innate immune cells via Toll-like receptor 2. PLoS ONE 2018, 13, e0193207. [CrossRef] [PubMed]

9. Girardin, S.E.; Travassos, L.H.; Herve, M.; Blanot, D.; Boneca, I.G.; Philpott, D.J.; Sansonetti, P.J.; Mengin-Lecreulx, D. Peptidoglycan molecular requirements allowing detection by Nod1 and Nod2. J. Biol. Chem. 2003, 278, 41702-41708. [CrossRef]

10. Sun, D.; Raisley, B.; Langer, M.; Iyer, J.K.; Vedham, V.; Ballard, J.L.; James, J.A.; Metcalf, J.; Coggeshall, K.M. Anti-peptidoglycan antibodies and Fcgamma receptors are the key mediators of inflammation in Gram-positive sepsis. J. Immunol. 2012, 189, 2423-2431. [CrossRef] [PubMed]

11. Girton, A.W.; Popescu, N.I.; Keshari, R.S.; Burgett, T.; Lupu, F.; Coggeshall, K.M. Serum Amyloid P and IgG Exhibit Differential Capabilities in the Activation of the Innate Immune System in Response to Bacillus anthracis Peptidoglycan. Infect. Immun. 2018, 86, e00076-18. [CrossRef] [PubMed]

12. Keshari, R.S.; Popescu, N.I.; Silasi, R.; Regmi, G.; Lupu, C.; Simmons, J.H.; Ricardo, A.; Coggeshall, K.M.; Lupu, F. Complement C5 inhibition protects against hemolytic anemia and acute kidney injury in anthrax peptidoglycan-induced sepsis in baboons. Proc. Natl. Acad. Sci. USA 2021, 118, e2104347118. [CrossRef] [PubMed]

13. Royet, J.; Gupta, D.; Dziarski, R. Peptidoglycan recognition proteins: Modulators of the microbiome and inflammation. Nat. Rev. Immunol. 2011, 11, 837-851. [CrossRef] [PubMed]

14. Chamaillard, M.; Hashimoto, M.; Horie, Y.; Masumoto, J.; Qiu, S.; Saab, L.; Ogura, Y.; Kawasaki, A.; Fukase, K.; Kusumoto, S.; et al. An essential role for NOD1 in host recognition of bacterial peptidoglycan containing diaminopimelic acid. Nat. Immunol. 2003, 4, 702-707. [CrossRef] [PubMed]

15. Faustin, B.; Lartigue, L.; Bruey, J.M.; Luciano, F.; Sergienko, E.; Bailly-Maitre, B.; Volkmann, N.; Hanein, D.; Rouiller, I.; Reed, J.C. Reconstituted NALP1 inflammasome reveals two-step mechanism of caspase-1 activation. Mol. Cell 2007, 25, 713-724. [CrossRef] [PubMed]

16. Popescu, N.I.; Silasi, R.; Keshari, R.S.; Girton, A.; Burgett, T.; Zeerleder, S.S.; Gailani, D.; Gruber, A.; Lupu, F.; Coggeshall, K.M. Peptidoglycan induces disseminated intravascular coagulation in baboons through activation of both coagulation pathways. Blood 2018, 132, 849-860. [CrossRef] [PubMed]

17. Jutras, B.L.; Lochhead, R.B.; Kloos, Z.A.; Biboy, J.; Strle, K.; Booth, C.J.; Govers, S.K.; Gray, J.; Schumann, P.; Vollmer, W.; et al. Borrelia burgdorferi peptidoglycan is a persistent antigen in patients with Lyme arthritis. Proc. Natl. Acad. Sci. USA 2019, 116, 13498-13507. [CrossRef] [PubMed]

18. Van Heel, D.A.; Ghosh, S.; Butler, M.; Hunt, K.A.; Lundberg, A.M.; Ahmad, T.; McGovern, D.P.; Onnie, C.; Negoro, K.; Goldthorpe, S.; et al. Muramyl dipeptide and toll-like receptor sensitivity in NOD2-associated Crohn's disease. Lancet 2005, 365, 1794-1796. [CrossRef]

19. Huang, Z.; Wang, J.; Xu, X.; Wang, H.; Qiao, Y.; Chu, W.C.; Xu, S.; Chai, L.; Cottier, F.; Pavelka, N.; et al. Antibody neutralization of microbiota-derived circulating peptidoglycan dampens inflammation and ameliorates autoimmunity. Nat. Microbiol. 2019, 4, 766-773. [CrossRef] [PubMed]

20. Iyer, J.K.; Khurana, T.; Langer, M.; West, C.M.; Ballard, J.D.; Metcalf, J.P.; Merkel, T.J.; Coggeshall, K.M. Inflammatory cytokine response to Bacillus anthracis peptidoglycan requires phagocytosis and lysosomal trafficking. Infect. Immun. 2010, 78, 2418-2428. [CrossRef] [PubMed]

21. Paradis-Bleau, C.; Markovski, M.; Uehara, T.; Lupoli, T.J.; Walker, S.; Kahne, D.E.; Bernhardt, T.G. Lipoprotein cofactors located in the outer membrane activate bacterial cell wall polymerases. Cell 2010, 143, 1110-1120. [CrossRef] [PubMed]

22. Typas, A.; Banzhaf, M.; Van den Berg van Saparoea, B.; Verheul, J.; Biboy, J.; Nichols, R.J.; Zietek, M.; Beilharz, K.; Kannenberg, K.; Von Rechenberg, M.; et al. Regulation of peptidoglycan synthesis by outer-membrane proteins. Cell 2010, 143, 1097-1109. [CrossRef] [PubMed]

23. Irazoki, O.; Hernandez, S.B.; Cava, F. Peptidoglycan Muropeptides: Release, Perception, and Functions as Signaling Molecules. Front. Microbiol. 2019, 10, 500. [CrossRef] [PubMed]

24. Marina-Garcia, N.; Franchi, L.; Kim, Y.G.; Hu, Y.; Smith, D.E.; Boons, G.J.; Nunez, G. Clathrin- and dynamin-dependent endocytic pathway regulates muramyl dipeptide internalization and NOD2 activation. J. Immunol. 2009, 182, 4321-4327. [CrossRef] [PubMed]

25. Nakamura, N.; Lill, J.R.; Phung, Q.; Jiang, Z.; Bakalarski, C.; De Maziere, A.; Klumperman, J.; Schlatter, M.; Delamarre, L.; Mellman, I. Endosomes are specialized platforms for bacterial sensing and NOD2 signalling. Nature 2014, 509, 240-244. [CrossRef]

26. Pathirana, R.D.; Kaparakis-Liaskos, M. Bacterial membrane vesicles: Biogenesis, immune regulation and pathogenesis. Cell Microbiol. 2016, 18, 1518-1524. [CrossRef] [PubMed]

27. Kaparakis, M.; Turnbull, L.; Carneiro, L.; Firth, S.; Coleman, H.A.; Parkington, H.C.; Le Bourhis, L.; Karrar, A.; Viala, J.; Mak, J.; et al. Bacterial membrane vesicles deliver peptidoglycan to NOD1 in epithelial cells. Cell Microbiol. 2010, 12, 372-385. [CrossRef] [PubMed] 
28. Thay, B.; Damm, A.; Kufer, T.A.; Wai, S.N.; Oscarsson, J. Aggregatibacter actinomycetemcomitans outer membrane vesicles are internalized in human host cells and trigger NOD1- and NOD2-dependent NF-kappaB activation. Infect. Immun. 2014, 82, 4034-4046. [CrossRef]

29. Mayer-Scholl, A.; Hurwitz, R.; Brinkmann, V.; Schmid, M.; Jungblut, P.; Weinrauch, Y.; Zychlinsky, A. Human neutrophils kill Bacillus anthracis. PLoS Pathog. 2005, 1, e23. [CrossRef]

30. Keshari, R.S.; Silasi, R.; Popescu, N.I.; Patel, M.M.; Chaaban, H.; Lupu, C.; Coggeshall, K.M.; Mollnes, T.E.; DeMarco, S.J.; Lupu, F. Inhibition of complement $\mathrm{C} 5$ protects against organ failure and reduces mortality in a baboon model of Escherichia coli sepsis. Proc. Natl. Acad. Sci. USA 2017, 114, E6390-E6399. [CrossRef] [PubMed]

31. Iyer, J.K.; Coggeshall, K.M. Cutting edge: Primary innate immune cells respond efficiently to polymeric peptidoglycan, but not to peptidoglycan monomers. J. Immunol. 2011, 186, 3841-3845. [CrossRef] [PubMed]

32. Popescu, N.I.; Girton, A.; Burgett, T.; Lovelady, K.; Coggeshall, K.M. Monocyte procoagulant responses to anthrax peptidoglycan are reinforced by proinflammatory cytokine signaling. Blood Adv. 2019, 3, 2436-2447. [CrossRef] [PubMed]

33. Popescu, N.I.; Keshari, R.S.; Cochran, J.; Coggeshall, K.M.; Lupu, F. C3 Opsonization of Anthrax Bacterium and Peptidoglycan Supports Recognition and Activation of Neutrophils. Microorganisms 2020, 8, 1039. [CrossRef]

34. Langer, M.; Malykhin, A.; Maeda, K.; Chakrabarty, K.; Williamson, K.S.; Feasley, C.L.; West, C.M.; Metcalf, J.P.; Coggeshall, K.M. Bacillus anthracis peptidoglycan stimulates an inflammatory response in monocytes through the p38 mitogen-activated protein kinase pathway. PLoS ONE 2008, 3, e3706. [CrossRef] [PubMed]

35. MacDonald, J.A.; Bothun, A.M.; Annis, S.N.; Sheehan, H.; Ray, S.; Gao, Y.; Ivanov, A.R.; Khrapko, K.; Tilly, J.L.; Woods, D.C. A nanoscale, multi-parametric flow cytometry-based platform to study mitochondrial heterogeneity and mitochondrial DNA dynamics. Commun. Biol. 2019, 2, 258. [CrossRef]

36. Peng, G.E.; Wilson, S.R.; Weiner, O.D. A pharmacological cocktail for arresting actin dynamics in living cells. Mol. Biol. Cell 2011, 22, 3986-3994. [CrossRef] [PubMed]

37. Dejonghe, W.; Sharma, I.; Denoo, B.; De Munck, S.; Lu, Q.; Mishev, K.; Bulut, H.; Mylle, E.; De Rycke, R.; Vasileva, M.; et al. Disruption of endocytosis through chemical inhibition of clathrin heavy chain function. Nat. Chem. Biol. 2019, 15, 641-649. [CrossRef]

38. Harper, C.B.; Martin, S.; Nguyen, T.H.; Daniels, S.J.; Lavidis, N.A.; Popoff, M.R.; Hadzic, G.; Mariana, A.; Chau, N.; McCluskey, A.; et al. Dynamin inhibition blocks botulinum neurotoxin type A endocytosis in neurons and delays botulism. J. Biol. Chem. 2011, 286, 35966-35976. [CrossRef] [PubMed]

39. Shang, X.; Marchioni, F.; Evelyn, C.R.; Sipes, N.; Zhou, X.; Seibel, W.; Wortman, M.; Zheng, Y. Small-molecule inhibitors targeting G-protein-coupled Rho guanine nucleotide exchange factors. Proc. Natl. Acad. Sci. USA 2013, 110, 3155-3160. [CrossRef]

40. Thottacherry, J.J.; Kosmalska, A.J.; Kumar, A.; Vishen, A.S.; Elosegui-Artola, A.; Pradhan, S.; Sharma, S.; Singh, P.P.; Guadamillas, M.C.; Chaudhary, N.; et al. Mechanochemical feedback control of dynamin independent endocytosis modulates membrane tension in adherent cells. Nat. Commun. 2018, 9, 4217. [CrossRef] [PubMed]

41. Karnik, R.; Ludlow, M.J.; Abuarab, N.; Smith, A.J.; Hardy, M.E.; Elliott, D.J.; Sivaprasadarao, A. Endocytosis of HERG is clathrin-independent and involves arf6. PLoS ONE 2013, 8, e85630. [CrossRef] [PubMed]

42. Benabdi, S.; Peurois, F.; Nawrotek, A.; Chikireddy, J.; Caneque, T.; Yamori, T.; Shiina, I.; Ohashi, Y.; Dan, S.; Rodriguez, R.; et al. Family-wide Analysis of the Inhibition of Arf Guanine Nucleotide Exchange Factors with Small Molecules: Evidence of Unique Inhibitory Profiles. Biochemistry 2017, 56, 5125-5133. [CrossRef]

43. Dziarski, R.; Tapping, R.I.; Tobias, P.S. Binding of bacterial peptidoglycan to CD14. J. Biol. Chem. 1998, 273, 8680-8690. [CrossRef]

44. Dixon, T.C.; Meselson, M.; Guillemin, J.; Hanna, P.C. Anthrax. N. Engl. J. Med. 1999, 341, 815-826. [CrossRef] [PubMed]

45. Popov, S.G. New Candidate Anthrax Pathogenic Factors; Springer: Totowa, NJ, USA, 2008; pp. 25-36. [CrossRef]

46. Coggeshall, K.M.; Lupu, F.; Ballard, J.; Metcalf, J.P.; James, J.A.; Farris, D.; Kurosawa, S. The sepsis model: An emerging hypothesis for the lethality of inhalation anthrax. J. Cell Mol. Med. 2013, 17, 914-920. [CrossRef] [PubMed]

47. Sweeney, D.A.; Hicks, C.W.; Cui, X.; Li, Y.; Eichacker, P.Q. Anthrax infection. Am. J. Respir. Crit. Care Med. 2011, $184,1333-1341$. [CrossRef] [PubMed]

48. Qiu, P.; Li, Y.; Shiloach, J.; Cui, X.; Sun, J.; Trinh, L.; Kubler-Kielb, J.; Vinogradov, E.; Mani, H.; Al-Hamad, M.; et al. Bacillus anthracis cell wall peptidoglycan but not lethal or edema toxins produces changes consistent with disseminated intravascular coagulation in a rat model. J. Infect. Dis. 2013, 208, 978-989. [CrossRef] [PubMed]

49. Sun, D.; Popescu, N.I.; Raisley, B.; Keshari, R.S.; Dale, G.L.; Lupu, F.; Coggeshall, K.M. Bacillus anthracis peptidoglycan activates human platelets through FcgammaRII and complement. Blood 2013, 122, 571-579. [CrossRef] [PubMed]

50. Canton, J.; Schlam, D.; Breuer, C.; Gutschow, M.; Glogauer, M.; Grinstein, S. Calcium-sensing receptors signal constitutive macropinocytosis and facilitate the uptake of NOD2 ligands in macrophages. Nat. Commun. 2016, 7, 11284. [CrossRef] [PubMed]

51. Loh, L.N.; Gao, G.; Tuomanen, E.I. Dissecting Bacterial Cell Wall Entry and Signaling in Eukaryotic Cells: An Actin-Dependent Pathway Parallels Platelet-Activating Factor Receptor-Mediated Endocytosis. mBio 2017, 8, e02030-16. [CrossRef] [PubMed]

52. Boucrot, E.; Ferreira, A.P.; Almeida-Souza, L.; Debard, S.; Vallis, Y.; Howard, G.; Bertot, L.; Sauvonnet, N.; McMahon, H.T. Endophilin marks and controls a clathrin-independent endocytic pathway. Nature 2015, 517, 460-465. [CrossRef]

53. Crowley, M.T.; Costello, P.S.; Fitzer-Attas, C.J.; Turner, M.; Meng, F.; Lowell, C.; Tybulewicz, V.L.; DeFranco, A.L. A critical role for Syk in signal transduction and phagocytosis mediated by Fcgamma receptors on macrophages. J. Exp. Med. 1997, 186, 1027-1039. [CrossRef] [PubMed] 
54. Shi, Y.; Tohyama, Y.; Kadono, T.; He, J.; Miah, S.M.; Hazama, R.; Tanaka, C.; Tohyama, K.; Yamamura, H. Protein-tyrosine kinase Syk is required for pathogen engulfment in complement-mediated phagocytosis. Blood 2006, 107, 4554-4562. [CrossRef] [PubMed]

55. Caron, E.; Hall, A. Identification of two distinct mechanisms of phagocytosis controlled by different Rho GTPases. Science 1998, 282, 1717-1721. [CrossRef] [PubMed]

56. Suzuki, T.; Kono, H.; Hirose, N.; Okada, M.; Yamamoto, T.; Yamamoto, K.; Honda, Z. Differential involvement of Src family kinases in Fc gamma receptor-mediated phagocytosis. J. Immunol. 2000, 165, 473-482. [CrossRef] [PubMed]

57. Abrami, L.; Bischofberger, M.; Kunz, B.; Groux, R.; Van der Goot, F.G. Endocytosis of the anthrax toxin is mediated by clathrin, actin and unconventional adaptors. PLoS Pathog. 2010, 6, e1000792. [CrossRef] [PubMed]

58. Harris, J.; Werling, D.; Hope, J.C.; Taylor, G.; Howard, C.J. Caveolae and caveolin in immune cells: Distribution and functions. Trends Immunol. 2002, 23, 158-164. [CrossRef]

59. Baorto, D.M.; Gao, Z.; Malaviya, R.; Dustin, M.L.; Van der Merwe, A.; Lublin, D.M.; Abraham, S.N. Survival of FimH-expressing enterobacteria in macrophages relies on glycolipid traffic. Nature 1997, 389, 636-639. [CrossRef] [PubMed]

60. Peyron, P.; Bordier, C.; N’Diaye, E.N.; Maridonneau-Parini, I. Nonopsonic phagocytosis of Mycobacterium kansasii by human neutrophils depends on cholesterol and is mediated by CR3 associated with glycosylphosphatidylinositol-anchored proteins. J. Immunol. 2000, 165, 5186-5191. [CrossRef]

61. Zimnicka, A.M.; Husain, Y.S.; Shajahan, A.N.; Sverdlov, M.; Chaga, O.; Chen, Z.; Toth, P.T.; Klomp, J.; Karginov, A.V.; Tiruppathi, C.; et al. Src-dependent phosphorylation of caveolin-1 Tyr-14 promotes swelling and release of caveolae. Mol. Biol. Cell 2016, 27, 2090-2106. [CrossRef] [PubMed] 